\title{
AN ESTIMATE OETHE POTENTIAL GROWTH OF THE SPANISH ECONOMY
}

Pablo Hernández de Cos.

Mario zantierdo and alberto ynasun.

Documentos ocasionales.

N. 1104

baneo españa

2011

\author{
Eurosistema
}


AN ESTIMATE OF THE POTENTIAL GROWTH OF THE SPANISH ECONOMY 
AN ESTIMATE OF THE POTENTIAL GROWTH OF THE SPANISH ECONOMY

Pablo Hernández de Cos, Mario Izquierdo and Alberto Urtasun (*) BANCO DE ESPAÑA

(*) E-mails: pablo.hernandez_de_cos@bde.es; mizquierdo@bde.es; aurtasun@bde.es. 
The Occasional Paper Series seeks to disseminate work conducted at the Banco de España, in the performance of its functions, that may be of general interest.

The opinions and analyses in the Occasional Paper Series are the responsibility of the authors and, therefore, do not necessarily coincide with those of the Banco de España or the Eurosystem.

The Banco de España disseminates its main reports and most of its publications via the INTERNET at the following website: http://www.bde.es.

Reproduction for educational and non-commercial purposes is permitted provided that the source is acknowledged.

(C) BANCO DE ESPAÑA, Madrid, 2011

ISSN: 1696-2222 (print)

ISSN: 1696-2230 (on line)

Depósito legal: M. 32853-2011

Unidad de Publicaciones, Banco de España 


\begin{abstract}
This paper seeks to estimate the potential output of the Spanish economy, using the production function methodology standard in the literature. According to these estimates, the growth of the potential output of the Spanish economy stood at around $3 \%$ in the period 2000-2007, owing to the marked increase in the population and in the participation rate and the fall in structural unemployment, as well as vigorous capital accumulation. The contribution of these factors to potential output was reduced by the negative evolution of total factor productivity. In addition, the economic crisis is estimated to have had a significant negative impact on potential output, which has primarily taken the form of a large increase in structural unemployment, a sharp slowdown in population growth, as a consequence of the loss of momentum in immigrant inflows, and a reduction in the contribution of the capital stock resulting from the impact of the crisis on investment. As a result, the potential growth of the Spanish economy stands at around 1\% during the crisis years and in the years immediately thereafter, insofar as some of these negative effects take place with a certain time lag. Lastly, in the medium term, the potential output of the economy is estimated to recover progressively, once the effects of the crisis have disappeared, reaching growth rates about $2 \%$, against a background of negative rates of change in the population of age 16-64, a smooth improvement in the NAIRU, a slight recovery in investment and a higher contribution from TFP. The application of a strong process of structural reforms could, however, significantly improve the growth prospects of our economy.
\end{abstract}

Keywords: Potential output, output gap, Spain.

JEL classification: E23, E32. 


\section{Introduction}

The potential growth of an economy is one of the most relevant concepts for economic analysis and, in particular, for economic policy decisions. Issues as important as the cyclical position of the economy and the assessment of the macroeconomic policy stance cannot be addressed without knowledge of this variable.

The potential output of the economy is not observable, however, and therefore has to be estimated. The estimation of potential output is not without controversy and, in fact, a large variety of methodologies has been proposed in the literature for its calculation. Moreover, the uncertainty involved in the estimation of potential output is especially high in an environment like the current one, in which it is difficult to determine the extent of the effects of the economic crisis on this variable.

In particular, there are arguments for thinking that the economic crisis may have had a negative effect on the current level of potential output through, for example, the fall in investment or the increase in structural unemployment resulting from, among other factors, the increase in long-term unemployment. However, the economic crisis may also have had a negative effect on the potential growth rate of the economy in the medium term if, for example, it leads to a permanent reduction in the economy's investment growth rate. This could be associated with greater risk aversion on the part of agents or a downward revision of future expectations for the economy, and/or a smaller contribution from potential employment as a consequence, among other factors, of a decline in migration flows. Conversely, the implementation of structural reforms that improve the functioning of product markets and economic factors could have a significant positive impact on the economy's potential growth in the medium term.

Against this background, this paper seeks to estimate the potential output of the Spanish economy. To do so it employs the production function methodology that is standard in the literature, with some modifications, mainly to reflect certain specific features of the Spanish economy. The basic advantage of this methodology is that it enables the underlying determinants of potential growth to be analysed. Moreover, in order to distinguish the more or less enduring effects of the recent economic crisis, not only is this estimation made for the observed period (1990-2009) and over a normal projection period for macroeconomic forecast exercises (2010-2012) ${ }^{1}$, but the analysis is extended to a medium-term horizon (2013-2015). Consideration of this medium-term horizon is particularly relevant given that the impact of the crisis on the level of potential output in estimates commonly available is in lower growth of this variable not only in the recession but also in the years immediately following, to the extent that some of these effects occur at a certain time lag. Therefore, the estimates for 2008-2012 cannot be taken as a projection of the growth rate of potential output of the economy in the medium and long term. In fact, it can be expected a gradual recovery of the economy's potential growth, once the effects of the crisis on the level of potential output are vanished. However, this medium term estimates need to take a series of assumptions about the evolution of the economy, which are particularly difficult, because normally there are no macroeconomic projections available for this time horizon. The results and interpretation of the results are therefore conditional to these assumptions.

1. See "Spanish Economic Projections Report", Economic Bulletin, April 2011, Banco de España. 
The following section details the methodology used to estimate potential output, Section 3 sets out the results and, finally, the main conclusions are presented in Section 4. 


\section{Methodology for estimating potential output}

\subsection{The production function}

The potential output of an economy can be estimated using different methodologies. These can basically be classified into those that use statistical procedures to estimate the trend in the economy's output, by separating out cyclical elements, and those that use a production function to estimate potential output ${ }^{2}$. In line with previous studies ${ }^{3}$, the approach followed in this paper is the latter one, since it is based on firmer theoretical concepts which, for example, enable the sources of potential growth to be analysed.

The first step in this estimation is to specify the form of the production function, the most commonly used being the Cobb-Douglas form. Assuming constant returns to scale, a Cobb-Douglas production function can be written as follows:

$$
Y=A L^{\propto} K^{1-\propto} P T F
$$

where $Y$ is output, A a scale factor, $\alpha$ the employment elasticity of output, $L$ employment, $K$ the capital stock and TFP total factor productivity, i.e. that part of growth that is not explained by changes in employment and capital. Within this framework, estimation of the economy's potential output, which we can denote by $Y^{*}$, requires the evaluation of the potential values of each of the components of the production function: employment, capital and TFP. In our case, this exercise is carried out solely for the market economy. To obtain potential output for the economy as a whole, the output of the public sector and indirect taxes net of subsidies are added to the potential output of the market economy.

Once potential output has been estimated, the output gap is defined simply as the difference, in percentage terms, between actual output and the estimated potential output.

$$
O G=\left(Y-Y^{*}\right) / Y^{*}
$$

There follows a description of the procedure for estimating the elasticity of output with respect to the factor of production labour $(\alpha)$ and of the components of potential output, namely employment, the capital stock and total factor productivity, as well as potential non-market output.

\subsection{The elasticity of output with respect to labour}

Starting from the above specification of the production function, taking differences, applying Euler's theorem and denoting with small letters the relevant variables in natural logarithms, we obtain that:

$$
\Delta y_{t}=\Delta a_{t}+\frac{\partial F}{\partial L} \frac{L}{Y} \Delta l_{t}+\frac{\partial F}{\partial K} \frac{K}{Y} \Delta k_{t}
$$

If, we also assume perfect competition in the product and factor markets, the first-order conditions for profit maximisation for the representative firm imply that the marginal

2. It is also possible to derive potential output within the framework of a DSGE model, as the output obtained with price flexibility.

3. See, for example, Estrada et al. (2004) and Izquierdo et al. (2007). 
productivity of each factor should be equal to its cost in real terms; therefore, in the case of the labour factor we can write:

$$
\frac{\partial F}{\partial L}=\frac{W}{P} \Rightarrow \frac{\partial F}{\partial L} \frac{L}{Y}=\frac{W L}{P Y}=S^{L}
$$

Where $S^{\llcorner}$represents the share of labour income in nominal output and implies that the employment elasticity of output is exactly equal to the share of labour income in nominal output. Given that the existence of constant returns to scale has been imposed, the elasticity of output with respect to capital will be precisely $\left(1-s^{L}\right)$.

In our case, we use annual National Accounts data to calculate this elasticity, although to avoid possible excessive fluctuations in this variable we use a series smoothed using the HP filter. With regard to the projection period, the value of the elasticity is estimated until 2012 using the forecasts of the "Spanish Economic Projections Report» published in the Banco de España April 2011 Economic Bulletin [Banco de España (2011)]; from 2013 it is held constant.

Chart 1 shows the importance of allowing the elasticity of output with respect to labour $(\alpha)$ to vary over time, since it has changed significantly during the period analysed. Specifically, one can see a clear downward trend in labour's share of income, not only in Spain but also in the euro area, although it is observed an increase of this variable since 2007 in the case of the euro area (see Chart 2). This trend may be associated with various factors, although in the case of Spain the strong growth in immigration, which is generally incorporated into the labour market with below average wages, must have contributed to moderating wage income until 2007. The moderation in these migratory flows during the crisis and in the subsequent period, in accordance with the available medium term estimations of the National Institute of Statistics (INE), justifies the stability projected for this parameter from 2013 onwards.

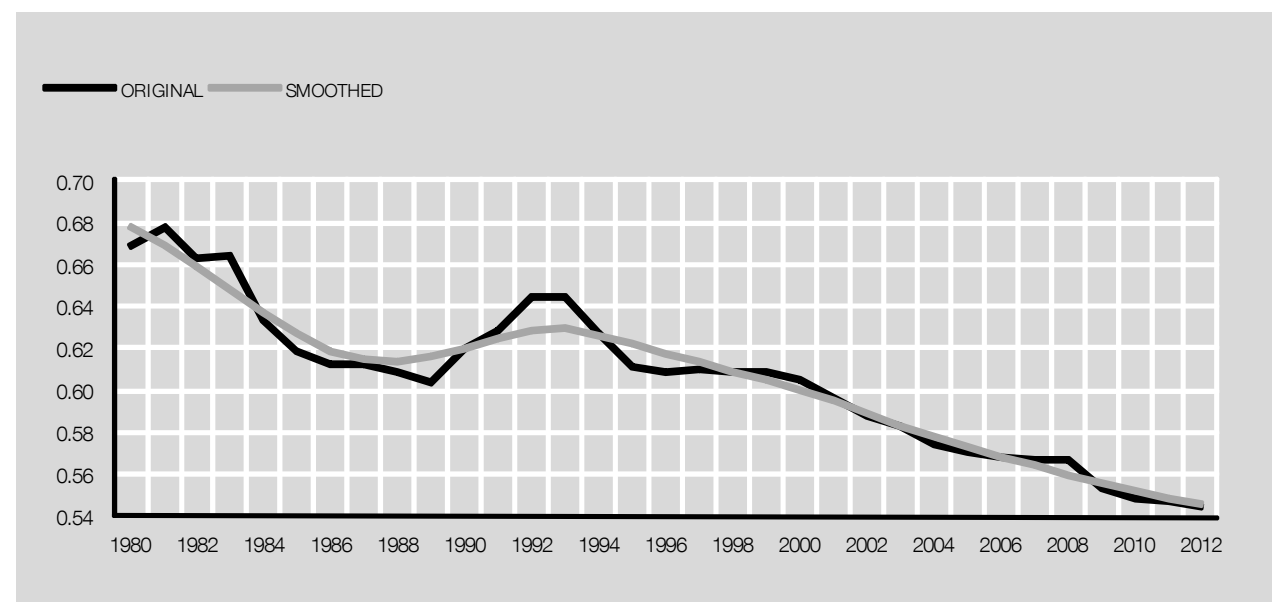

SOURCES: Instituto Nacional de Estadística and Banco de España. 

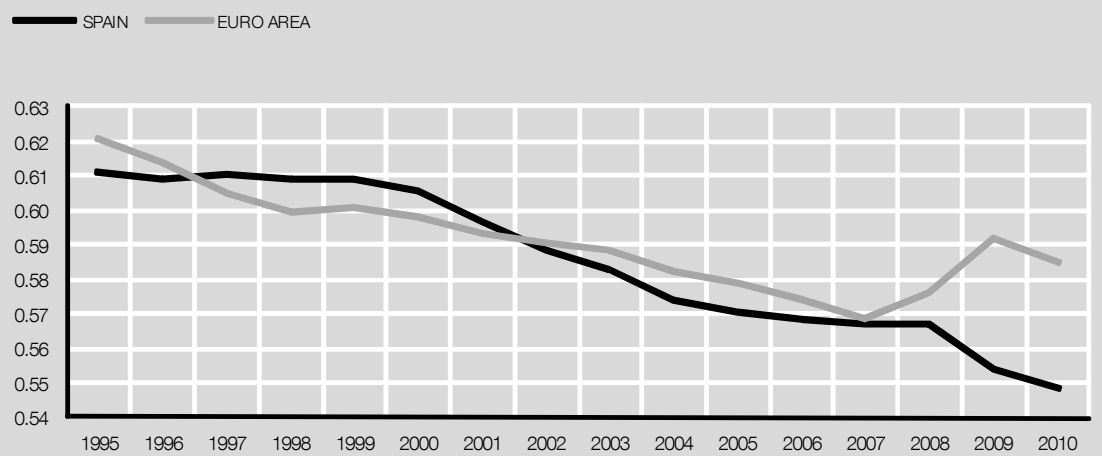

SOURCES: Instituto Nacional de Estadística and Eurostat.

\subsection{Potential employment}

The calculation of the economy's potential output is based on the following expression:

$$
L=L F \cdot(1-U)=P O P \cdot P R \cdot(1-U)
$$

where the level of employment (L) is defined as the labour force (LF) multiplied by the inverse of the unemployment rate $(\mathrm{U})$, and, where the labour force is decomposed into the product of the population over the age of 16 (POP) and the participation rate (PR). In addition, employment is measured as total hours worked, so that in the previous expression, $\mathrm{L}$ should be multiplied by the hours worked per person employed. Starting from this decomposition of employment, the economy's potential employment is calculated by estimating the potential values of each of the components mentioned: population, participation rate, unemployment rate and hours worked.

In the case of population, to estimate potential output the working age population is used, i.e. the population aged between 16 and 64, which is published by the INE in its annual National Accounts $(\mathrm{NA})^{4}$ estimates. In principle, population is a variable that is not affected by the business cycle, at least in the short term, since current fertility decisions only affect growth in the working age population 16 years on. However, in recent years migratory flows account for a fundamental part of population changes in Spain and these flows may indeed respond to the cyclical situation. Lacuesta and Puente (2009) have shown, using information on bilateral flows of immigration to OECD countries, that inflows of migrants have a positive, albeit not very large, elasticity with respect to per capita GDP. In fact, although there was a significant rise in population growth from the mid-1990s, associated with the entry of immigrants, to over $1.5 \%$ from 2001, this growth moderated sharply from 2008, which may have been at least partly due to the economic crisis. Accordingly, to avoid the cyclical component of population affecting the estimation of potential output, a smoothed population series is obtained, by applying the HP filter to the original series (see Chart 3).

4. This population series is fully consistent with the one estimated by the LFS, so that there are no problems of inconsistency with the unemployment series which, as we shall see further on, are based on this survey. In addition, the quarterly estimates supplied by the LFS may be used to assess the short-term population predictions. 


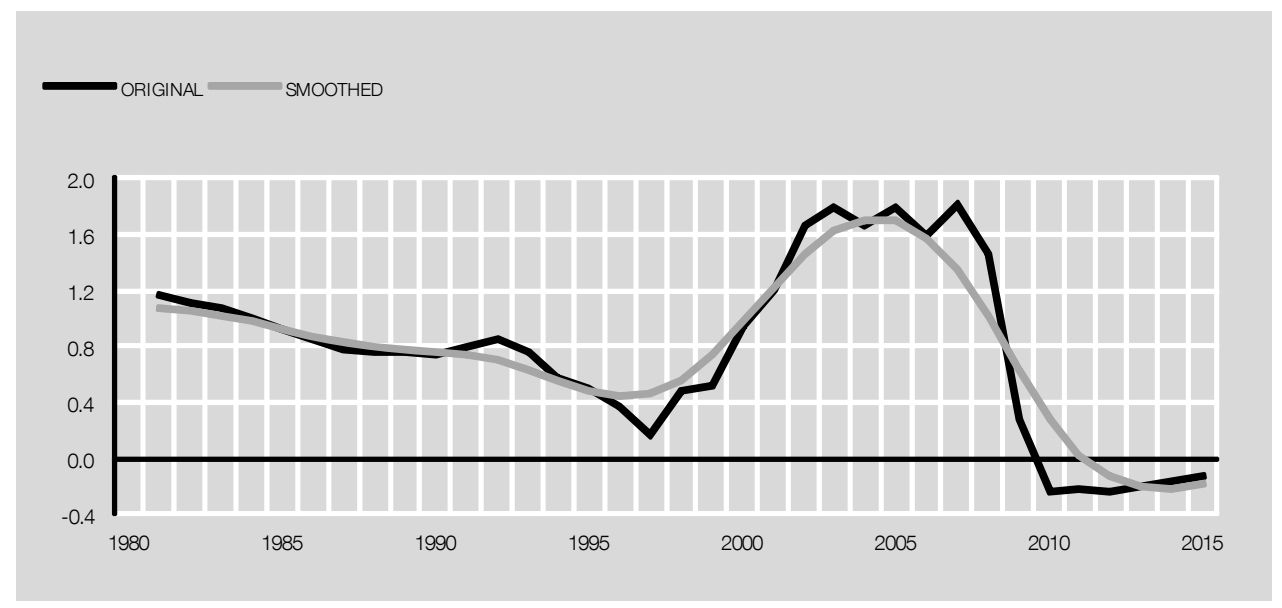

SOURCES: Instituto Nacional de Estadística and Banco de España.

As regards the population projections, INE forecasts are available for the period 2011-2015. These forecasts are used to project changes in the working age population and they anticipate a further slowdown in migratory flows, on top of that already observed since the start of the crisis, which will even lead to a decline in the working age population in future years, accompanied by a progressive ageing of the population of Spanish nationals.

With respect to the participation rate, it is defined for the purposes of the calculation of potential output as the sum of persons employed according to the National Accounts and persons unemployed according to the Spanish Labour Force Survey (LFS) as a percentage of the population between the ages of 16 and 64. This definition therefore uses National Accounts employment rather than LFS employment, to ensure consistency with the GDP estimates, which are based on the National Accounts. Chart 4 shows, however, that the differences between the two series are not excessive, although the participation rate as defined grows somewhat more slowly than that calculated on the basis of the LFS between 1995 and 2005, due to the lower employment growth estimated by the National Accounts during this period.

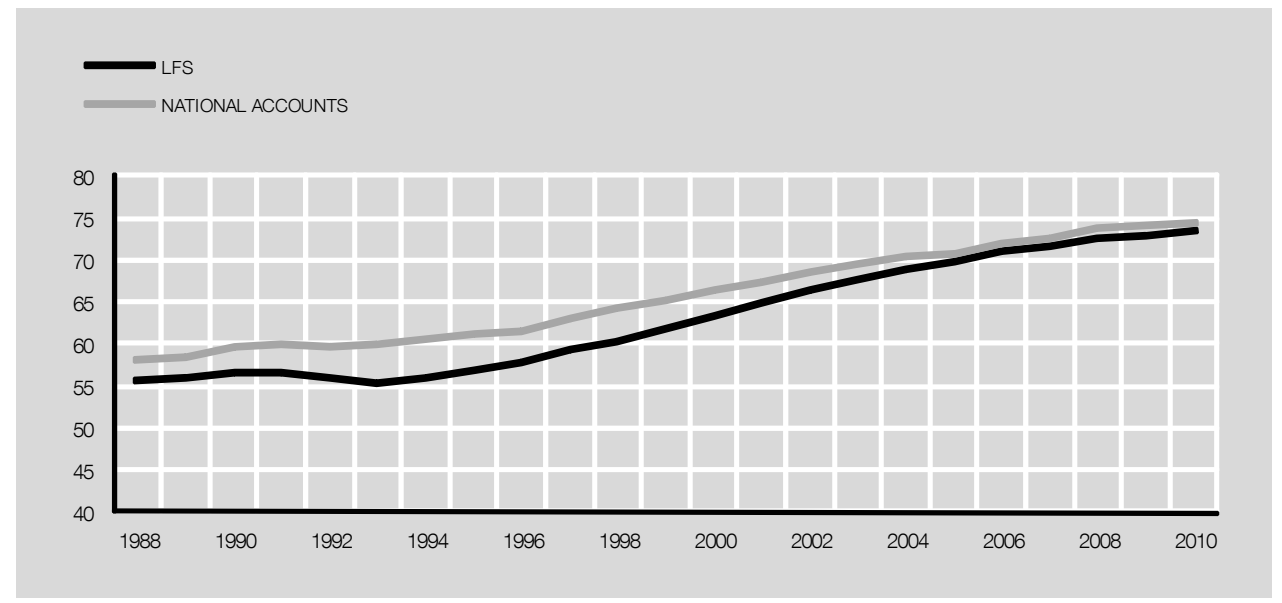

SOURCES: Instituto Nacional de Estadística and Banco de España. 
As regards estimation of the potential evolution of this variable, the participation rate may also behave cyclically as a consequence, for example, of disincentives to participation at times of high unemployment. However, high rates of unemployment which affect the main household earners, may also lead to an increase in the participation of individuals who would normally be outside the labour force. In order to capture these cyclical effects, we have estimated a relationship between the participation rate and the unemployment rate. This equation, with data to 2010 , gives an elasticity of -0.15 (t-statistic $=2.62$ ), i.e. on average a decline of $1 \mathrm{pp}$ in the unemployment rate leads to an increase of $0.15 \mathrm{pp}$ in the participation rate [see Montero (2011)]. To calculate the potential participation rate an equation is used in which the observed unemployment rate is replaced by the value of NAIRU, which we will analyse below. This procedure smooths the participation rate, since falls in unemployment are passed through to increases in the participation rate only insofar as they are considered to be structural (see Chart 5).

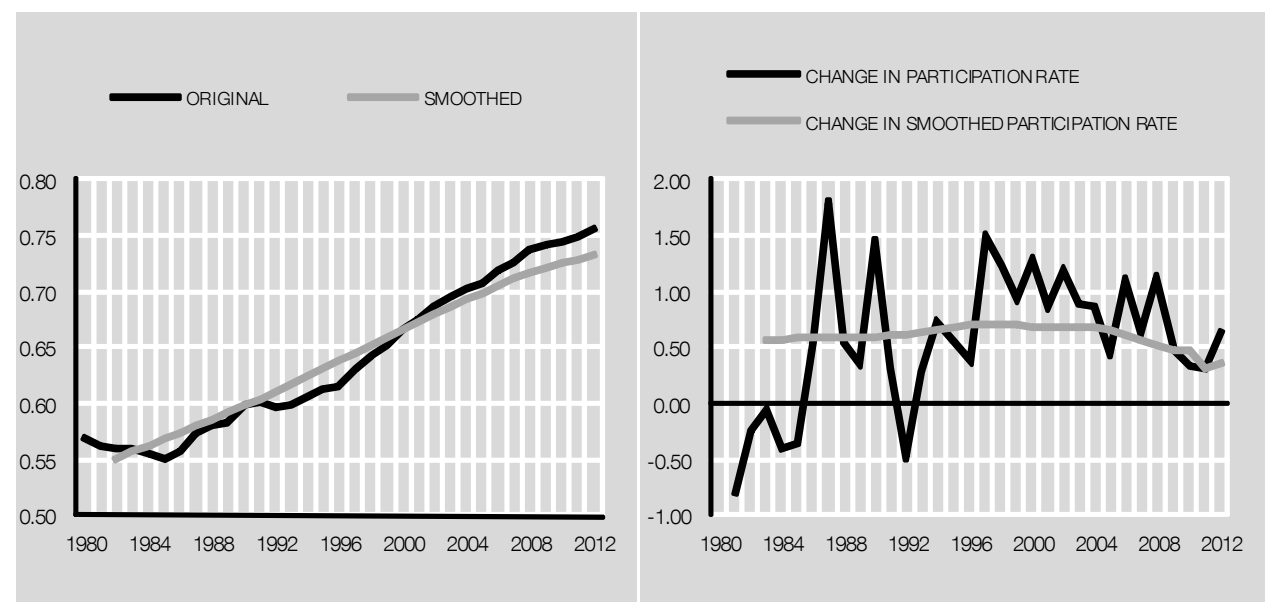

SOURCES: Instituto Nacional de Estadística and Banco de España.

With regard to the projection period, there is evidence that the cohort effect associated with the incorporation of women into the labour market -the main factor accounting for the increase in the participation rate in recent years ${ }^{5}$ - will continue to be the main determinant of the evolution of the potential participation rate in the next few years [see Cuadrado et al. (2007)], although its magnitude will be progressively smaller. Thus, for the projection period, the potential participation rate reflects both the effect of the changes in the structural component of unemployment and the available projections of this cohort effect. Specifically, demographic effects (which include the cohort effect of women's increasing participation in the labour market and that associated with a better educated population) explain an increase of $0.5 \mathrm{pp}$ in the aggregate participation rate of the population aged 16 to 64 in 2010, which slowly declines thereafter to an increase of around $0.3 \mathrm{pp}$ in 2015.

5. In fact, in Montero (2011) shows that the constant of a recursive regression between the change in the participation rate and the change in the unemployment rate (with data up to 2010), which would show the medium term trend of participation which in turn could be linked, at least in part, with so-called cohort effect, has a growing trend that tends to stabilize around 0.4 percentage points per year towards the end of the sample, in line with the effects cohort estimated in Cuadrado et al. (2007). 
Estimation of the rate of structural unemployment or NAIRU is subject to a high degree of uncertainty [see for example Estrada, Hernando and López Salido (2000)]. We have opted to estimate NAIRU using a Phillips curve type model in which changes in NAIRU are determined by a set of structural factors. Wage acceleration in this model depends on the unemployment gap, i.e. the difference between the actual rate of unemployment and NAIRU and changes in unemployment are allowed to have an impact on wage developments. This term therefore includes a hysteresis effect since, irrespective of the size of the unemployment gap, an increase/decrease in unemployment will affect wages.

$$
\Delta^{2} w=\beta\left(U_{t}-U^{*}\right)-\delta \Delta U_{t-1}+\varepsilon_{1 t}
$$

$\operatorname{NAIRU}\left(U^{\star}\right)$ itself follows a random walk with drift $\left(Z_{t}\right)$. The drift is affected by a set of structural factors, which therefore determine the changes in NAIRU.

$$
U_{t}^{*}=U_{t-1}^{*}+Z_{t}+\varepsilon_{2 t}
$$

Specifically, $Z_{t}$ includes the change in direct labour taxes, which positively affect NAIRU, by raising employment costs, and the change in the participation of women and immigrants in the labour force, which reduce NAIRU by introducing flexibility into the labour market. The results of the estimation using a Kalman filter for the period 1980-2008 are as follows ${ }^{6}$ :

$$
\begin{aligned}
& \Delta^{2} w= \underset{(-5.84)}{-0.35\left(U_{t}-U^{*}\right)-0.51 \Delta U_{t-1}}(-3.38) \\
& \Delta U_{t}^{*}=\underset{(2.42)}{0.89 T a x}-\underset{(-2.28)}{0.74}(\text { fpart }+ \text { Ipart })
\end{aligned}
$$

First, wages are seen to be relatively insensitive to the NAIRU GAP, given that the estimated coefficient $(-0.35)$ is towards the bottom end of the range of estimates available for other countries. At the same time, the hysteresis term associated with the impact of the change in unemployment on wages is clearly significant.

As regards the structural factors that affect NAIRU, as expected, taxes on labour have a positive impact on NAIRU, while female and immigrant labour force participation tends to reduce the Spanish economy's NAIRU. This result is consistent with, for example, the results of Bentolila et al. (2008), who estimate a large contribution by immigration to the flattening of the Phillips curve observed in the Spanish economy since 2000. That is to say, immigration contributed to ensuring that the decline in the rate of unemployment between 2000 and 2007 was not passed through to inflationary pressures, basically because of the lower reservation wage of this group of workers.

The projection of NAIRU makes use of the relationship between structural and long-term unemployment (see Chart 6). The latter is a relatively easy variable to predict once unemployment forecast are available. As for the other variables, until 2012 forecasts for the unemployment rate are taken from the Banco de España April 2011 "Spanish Economic Projections Report". From 2013 it is assumed an evolution of this variable similar to its behaviour at the end of the recession in 1993 (see Chart 7).

6. This estimation requires an assumption to be made regarding the relative variance of the error terms of the two equations. This assumption does not, however, affect the estimated level of NAIRU too much, but does affect its volatility. For the results presented below it was assumed that the variance of $\varepsilon_{2}$ is one third of the variance of $\varepsilon_{1}$. 


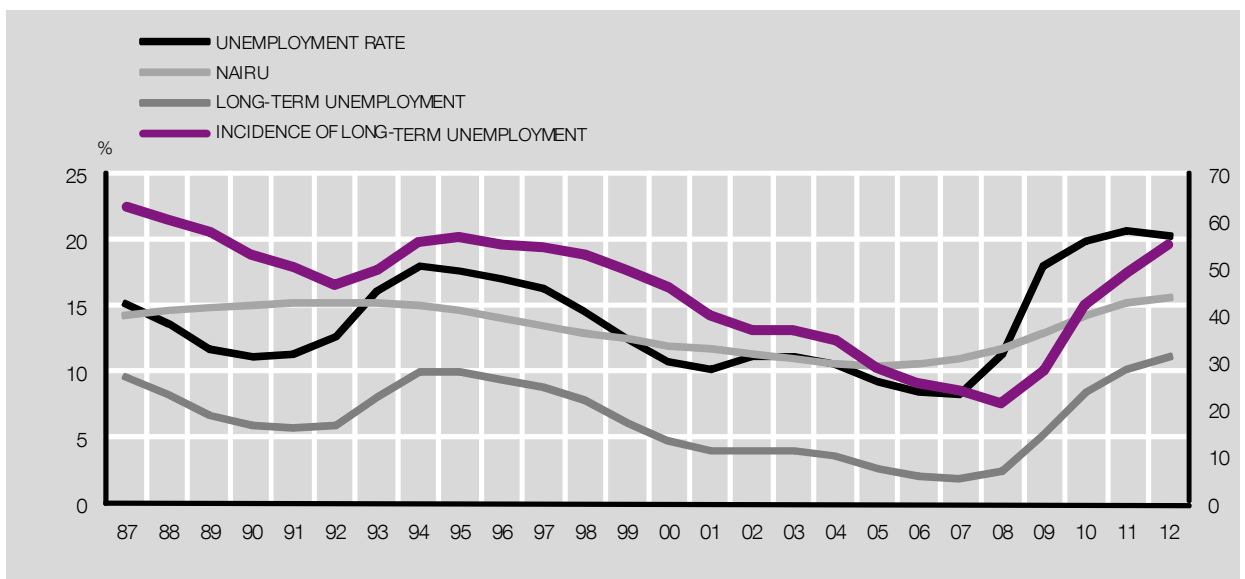

SOURCES: Instituto Nacional de Estadítica and Banco de España.

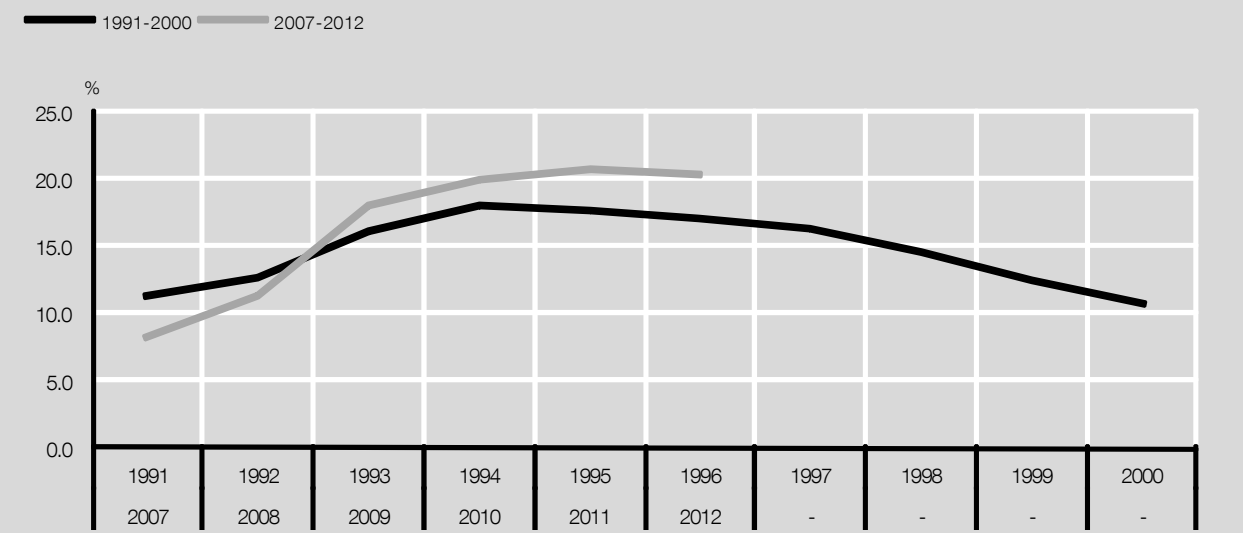

SOURCES: Instituto Nacional de Estadística and Banco de España.

The projection process is carried out in several stages. First an equation is estimated to explain the incidence of long-term unemployment on the basis of the unemployment rate (lagged by one period) and the rate of growth of employment (also in t-1); the coefficients of this equation have the expected signs and its $R^{2}$ is 0.98 . When the incidence of long-term unemployment has been projected, the forecast of long-term unemployment is obtained as the product of this variable and the rate of unemployment. Second, an equation is estimated relating NAIRU to long-term unemployment, and the coefficients of this regression are used to project structural unemployment (see Chart 6). As a result, NAIRU reaches over 16\%, peaking in 2011 and 2012, falling thereafter to slightly over 14\% in 2015.

Finally, to express potential employment in terms of total hours worked we use the information on hours worked per person employed available in the National Accounts estimates. Again in this case, one cannot rule out a certain cyclical component in the evolution of this variable, associated for example with greater or lesser intensity in the use of overtime, so that this series needs to be smoothed to avoid cyclical fluctuations. The HP filter 
is also used for this smoothing. As seen in Chart 8, hours per person employed have displayed a downward trend throughout the period with the exception of the years 2008, 2009 and 2010. As for the projection period, the decline in hours worked continues, but at a slower rate than in the 1980s. In this respect, it should be recalled that the structure of the Spanish labour market, in particular the high proportion of temporary employment, means that adjustments in employment basically occur through changes in the number of jobs and not in the hours worked per person. For the same reason, as the economy emerges from the crisis and especially in the medium term, the growth in the use of the labour factor can be expected to give rise to an increase in employment, without large changes in hours worked per person.

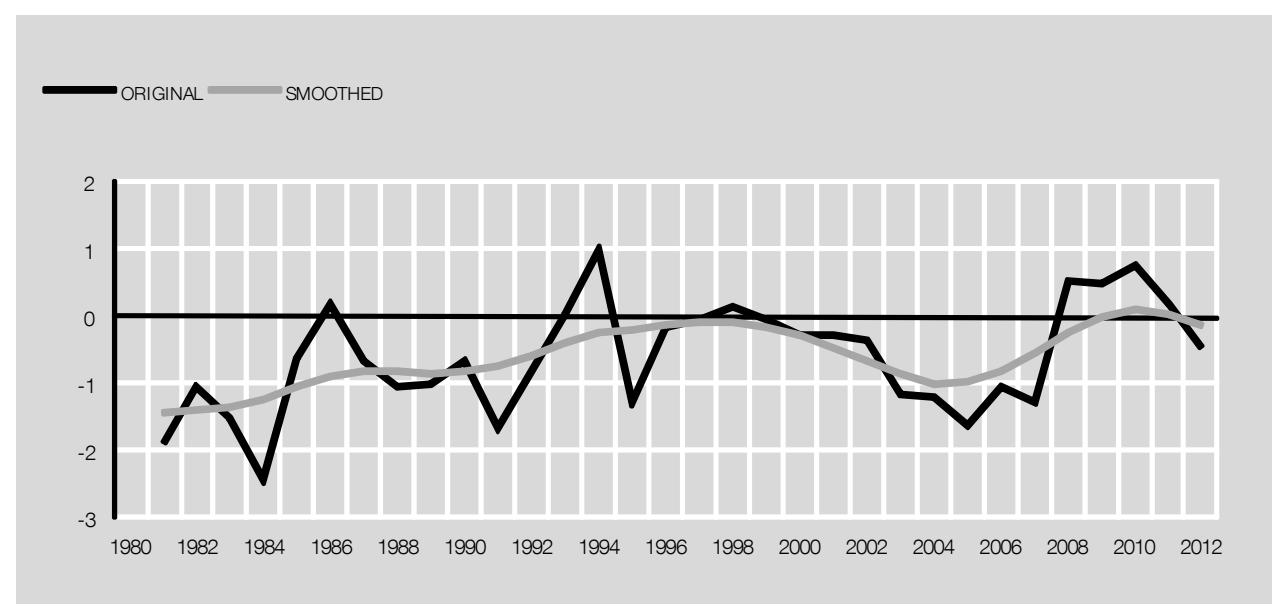

SOURCES: Instituto Nacional de Estadística and Banco de España.

\subsection{The potential capital stock}

The second basic input to estimate the economy's potential output is the capital stock. However, unlike the other primary factor of production (employment), this variable is not estimated directly in the National Accounts, so that it has to be obtained from other information sources. The capital stock is usually calculated on the basis of gross fixed capital formation, using the following accumulation formula [Hulten and Wyckoff (1981)]:

$$
K_{t}=\left(1-\delta_{t-1}\right) K_{t-1}+I_{t}
$$

where $\mathrm{K}$ is the capital stock, $\delta$ the rate of depreciation and $\mathrm{I}$ is gross fixed capital formation. Thus, in each time period the capital stock is obtained as the sum of the capital stock in the initial period ${ }^{7}$, having deducted the portion that has depreciated ${ }^{8}$, plus new acquisitions of capital goods.

7. Estimating the capital stock in the initial period is not without difficulty, since this is normally a distant period, for which information is not available. To avoid this problem one can resort to the first order condition for maximisation of the representative firm's profits, which implies that the productivity of capital must be equal to its user cost in real terms. Assuming that the production function is of the Cobb-Douglas type, with constant returns to scale, this condition implies that the ratio of capital to GDP will be equal to the inverse of the user cost of capital multiplied by the inverse of the elasticity of output with respect to capital. In addition, in the steady state investment must be equal to the specific percentage of the capital stock which coincides precisely with the rate of depreciation. Accordingly, the investment and GDP data estimated in the National Accounts can be used along with the rate of depreciation of the capital stock and its 
The capital stock can be disaggregated into three basic components ${ }^{9}$ : a) residential, b) public and c) private productive. These three components differ in terms of their useful life (their rate of depreciation) and their productivity (their unit contribution to production), which suggests that they should be constructed separately and that they should not be aggregated by simply adding them all together. Thus, for example, the annual rate of depreciation normally used in the case of residential investment is $2 \%$, which means that dwellings last around 50 years, whereas a rate of $4 \%$ is used for public investment and $10 \%$ for private productive investment. Such a low rate of depreciation for residential investment makes the housing stock very large in relative terms (around 60\% of the total), even though residential investment only accounts for $10 \%$ of total gross fixed capital formation. However, National Accounts data show that the imputed rentals for owner-occupied housing represent less than $10 \%$ of the private sector's output. It is therefore evident that the "productivity" of this investment is lower than that of other investment and, consequently, the housing stock should be reweighted before being aggregated.

This correction of the levels of the stocks of capital in accordance with their productivity is one of the main contributions of the EU-KLEMS database [O'Mahony and Timmer (2009)], which is the one used for this paper. In this database the levels of the capital stocks of each type of investment are "corrected" in accordance with their cost relative to total capital costs. This means that residential capital, which has a low rate of depreciation and, therefore, a lower user cost is corrected downwards, as is the case of infrastructure. The opposite occurs in the case of private productive capital. Chart 9 shows the annual rates of change in the aggregate capital stock when its three components are simply summed and when each component is weighted by its productivity ${ }^{10}$. The latter is seen to display large cyclical fluctuations, growing more in expansionary periods and adjusting more in recessions.

user cost in real terms to obtain the capital stock. However, given that these are long-run equilibrium conditions and that there may be rigidities in the short run that prevent their continuous satisfaction, it is normal to estimate the capital stock using average data over several years (up to 10) that are sufficiently distant from the first year.

8. In principle, the rate of depreciation should reflect the loss of efficiency of the existing capital stock and, therefore, should show some variation over time, increasing in periods in which the capital stock is used more intensely, when significant technological progress is made and when demand shifts towards other products. However, to facilitate its calculation it is normal to consider it stable over time for each capital good, defined more or less restrictively, and its value is usually obtained from tax data on the charges made by firms for the amortisation of tangible fixed assets.

9. The residential component includes capital used to obtain accommodation services, including owner-occupied and rented housing. Public investment largely constitutes the infrastructure of a country. Finally, private productive investment includes machinery, buildings, transport equipment, etc., which firms use in their productive processes.

10. The latest capital data available in EU KLEMS relate to 2007. 


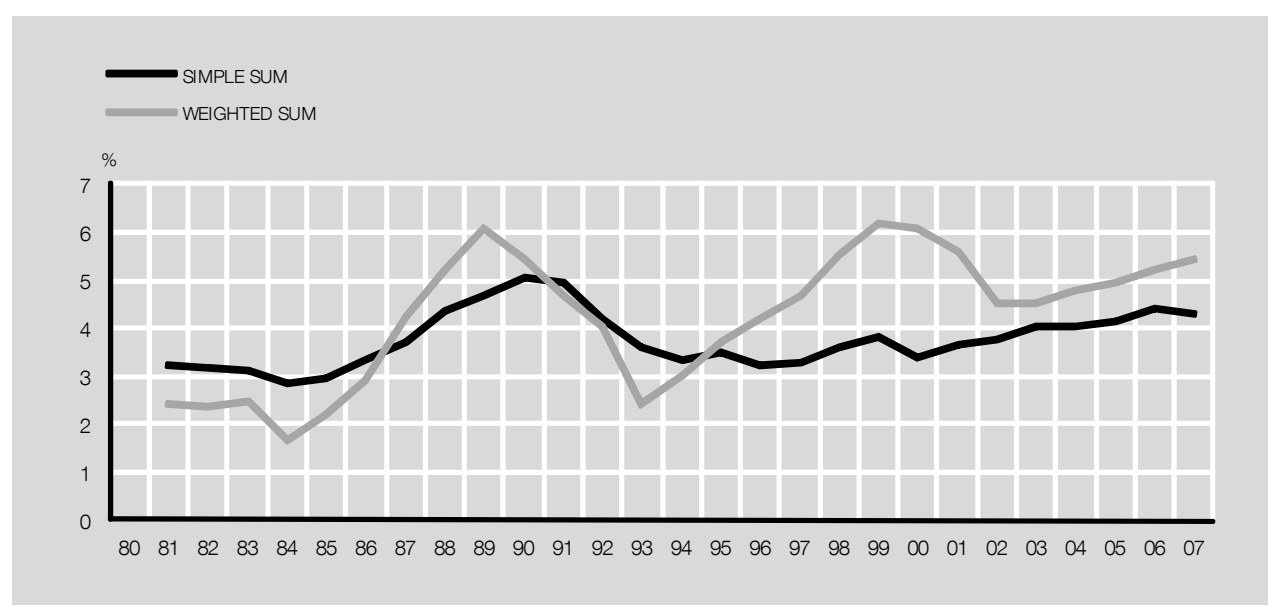

SOURCES: EUKLEMS, BBVA and Banco de España.

In order to obtain the economy's potential output it is necessary also to obtain the economy's potential stock of capital. Most studies that apply the production function methodology equate the potential stock of capital with the observed stock, given that the latter is barely correlated with the business cycle ${ }^{11}$. The explanation for this low correlation lies in the magnitude of the rate of depreciation: if it is very low (the useful life of the capital good is very long) the weight in the stock of investment is very small and, therefore, the stock is hardly affected by cyclical fluctuations in the flow ${ }^{12}$. However, in our case, when we correct the different capital stocks for their productivity, the assets that are depreciated most gain in weight, so that the capital stock used displays a significant positive correlation with the business cycle. Accordingly, it is not possible to equate the economy's potential capital stock with the actual stock, since this would induce a pro-cyclical bias into potential growth. To avoid this problem, the economy's potential capital stock is approximated by smoothing the observed capital stock using an HP filter which eliminates the fluctuations in this variable in the frequency of the business cycle (see Chart 10).

11. In fact, in most developed countries there is a statistic which tries to measure the percentage of installed productive capacity actually being used at each moment in time (in industry). This percentage fluctuates appreciably over time and displays a high positive correlation with the business cycle.

12. As the rate of depreciation increases (i.e. the useful life of the stock falls) the contribution of new investment becomes more important and the stock becomes more sensitive to the behaviour of the flow. 


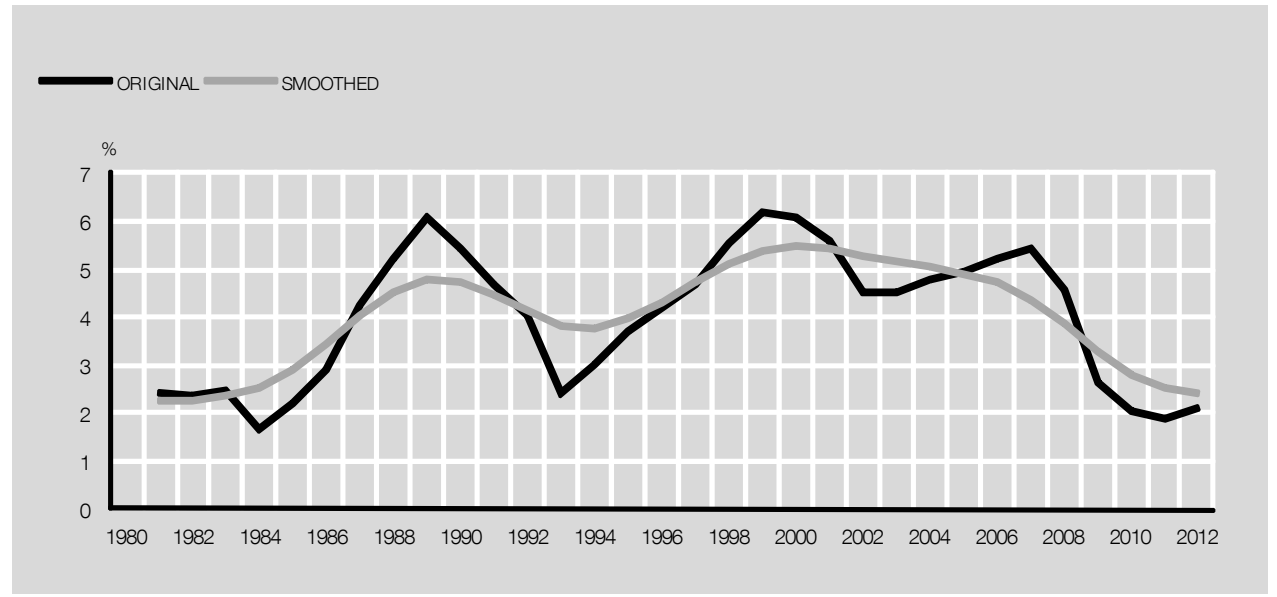

SOURCES: EUKLEMS and Banco de España.

Beyond the observed period, the capital stock is projected using the forecasts of the "Spanish Economic Projections Report" [Banco de España (2011)] for the different components of investment: private productive, public and residential. In addition, from 2013 we use the projections of this variable obtained with the Quarterly Macroeconometric Model of the Banco de España (MTBE, by its Spanish initials). This model uses the profit optimisation problem to obtain the long-run equilibrium conditions for the demand for capital, which depend on the ratio of the marginal productivity of capital being equal to the ratio of its nominal cost. For the projection period it is assumed that the real equilibrium interest rate will not return to the levels seen prior to the stage immediately before the crisis, when it was practically zero, but that it will stand at around 2\%, close to its level between 1996 and 1999. This permanent increase in interest rates can be justified by the foreseeable increase in risk premiums associated with more risk averse behaviour on the part of investors following the economic crisis, although it may also be interpreted as an increase in the market price of credit associated with a reduction in competition in the financial sector and/or stricter regulation, also as a consequence of the crisis. As a result of these assumptions investment evolution is expected to be very similar to that observed in the recession of the early nineties (see Chart 11).

PRIVATE PRODUCTIVE INVESTMENT: COMPARISON OF PROJECTIONSTO THE PREVIOUS CYCLE

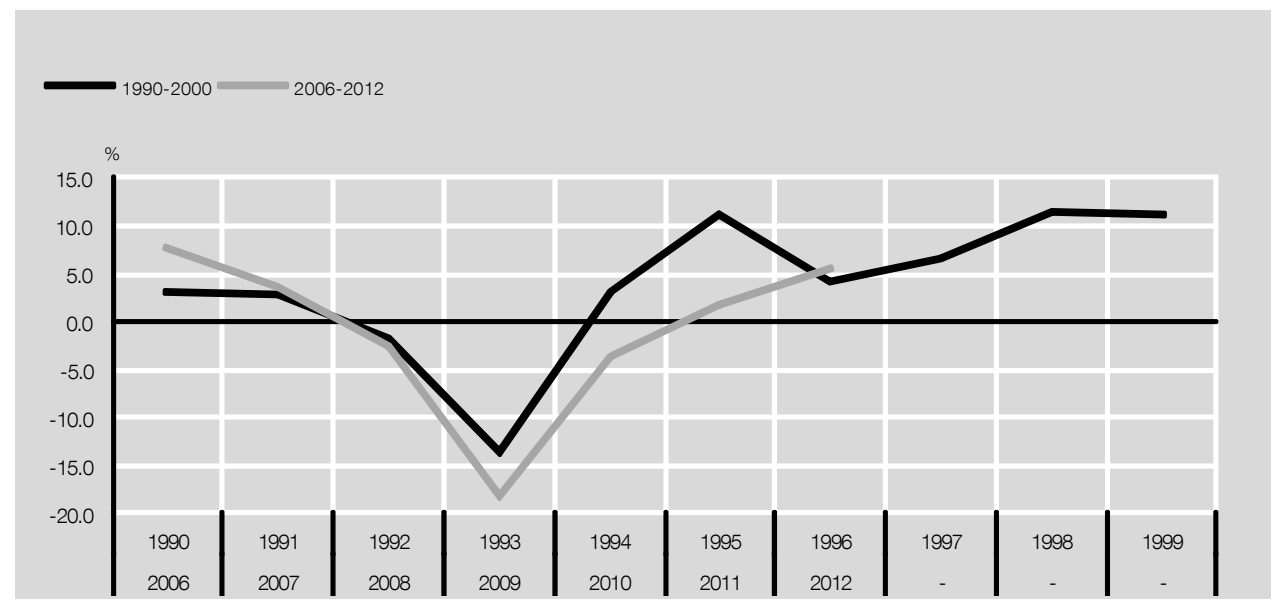

SOURCES: Instituto Nacional de Estadística and Banco de España. 


\subsection{Total factor productivity (TFP)}

Total factor productivity is defined as that part of output which cannot be justified by the existing factor endowment and by the factor combinations determined by current technology ${ }^{13}$. In consequence, the usual way of obtaining a series for TFP (A) in the observed period is as a residual of output $(Y)$, employment $(L)$ and the capital stock $(K)$. Specifically, the change in TFP can be obtained from the following expression, all the variables of which are observable:

$$
\Delta a_{t}=\Delta y_{t}-s_{t}^{L} \Delta l_{t}-\left(1-s_{t}^{L}\right) \Delta k_{t}
$$

There are two basic problems using this estimation of TFP to estimate potential output. First, given its residual nature it may display excessive fluctuations at the highest frequencies, since it includes all the errors in measuring output and the primary factors of production. Second, it may also display some correlation with the business cycle. Indeed, there is empirical evidence for many countries showing that TFP is positively correlated with the cycle. This may be due to a number of factors, although the most common explanations are that the capital stock is not always used with the same intensity ${ }^{14}$ and labour does not always perform its tasks with the same degree of effort. In fact, there is evidence that at the start of recessions "labour hoarding" occurs, whereby firms prefer not to lay off workers although activity has fallen, since both firing and hiring have a cost.

In Spain, the empirical evidence does not show a positive correlation between TFP (estimated as a residual) and the cycle, mainly due to the particular features of the labour market which mean that the bulk of adjustment falls on temporary employment. However, it does display a high short-run variability, as can be seen in Chart 12. In addition, as already mentioned, the capital stock series is not corrected for the use made of such stock. However, as can be seen in Chart 13, capacity utilisation is strongly cyclical and has fallen significantly during the present crisis. As a result, the TFP estimated without correcting for this phenomenon displays a strong fall during 2008 and 2009. In order to eliminate this effect, at least partially, we chose to apply the HP filter to the TFP to obtain its potential value (see Chart 12).

13. TFP is therefore a measure of the degree of economists' ignorance of the productive process. However, its unobservable and residual nature has not stopped theoretical and empirical analysis to try to identify its determinants. In particular, this variable has been related to technological innovation and, therefore, to indicators like investment in R\&D\&I, patents approved, etc. It may also reflect the institutional environment in which firms operate, so that indicators of the degree of competition in product markets or the degree of labour market rigidity are also crucial. The quality of human capital used by firms is another explanatory factor that may lie behind the behaviour of this residual. Finally, the quality of physical capital is a determinant that has also been analysed in the literature and, specifically, the role played by infrastructure in facilitating production by private firms.

14. As mentioned in the previous section there is a variable that measures capacity utilisation in industry, which displays a very close positive correlation with the business cycle. 


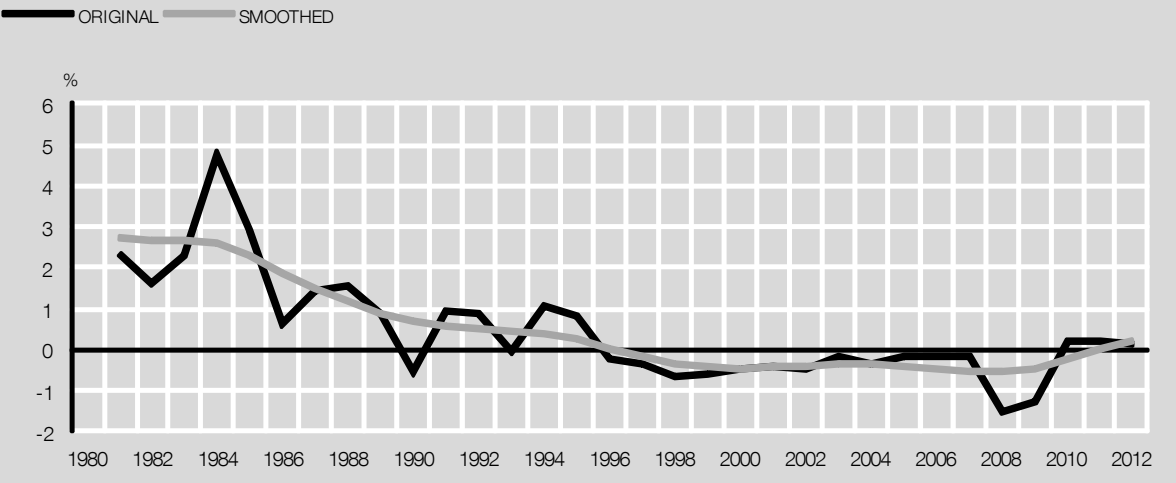

SOURCES: INE and Banco de España.

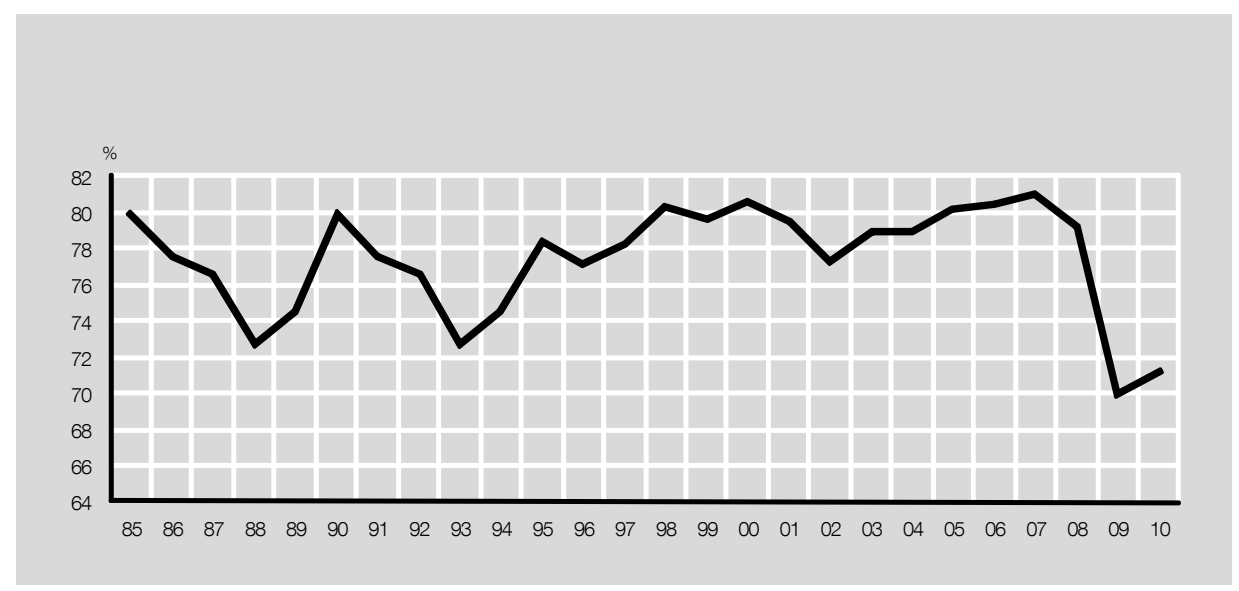

SOURCE: European Commission.

With regard to the projection period, the characteristics that explain the developments in TFP in the Spanish economy in recent years need to be taken into account. Specifically, the upswing in the economy was characterised by a progressive rise in the importance of the construction sector, whose weight peaked at $17.9 \%$ in $2006^{15}$. Insofar as this sector has a significantly lower productivity level and growth rate than the other sectors and the process of sectoral recomposition initiated during the crisis is expected to continue over the next few years, the TFP projection requires that this variable be analysed at a disaggregated level by sector. Specifically, this disaggregated analysis (see Chart 14) shows that the aggregate dynamics of TFP ${ }^{16}$ during the expansionary period are explained not only by the greater weight of the construction sector but also by the negative trend in this variable in the market services sector. In this latter case, however, there was a positive trend in TFP growth.

15. In current prices.

16. The weighted sum of TFP by sector does not coincide with the TFP used to calculate potential output since, on one hand cross products are not included and on the other, the HP filter is not applied to the series in the disaggregated analysis. 

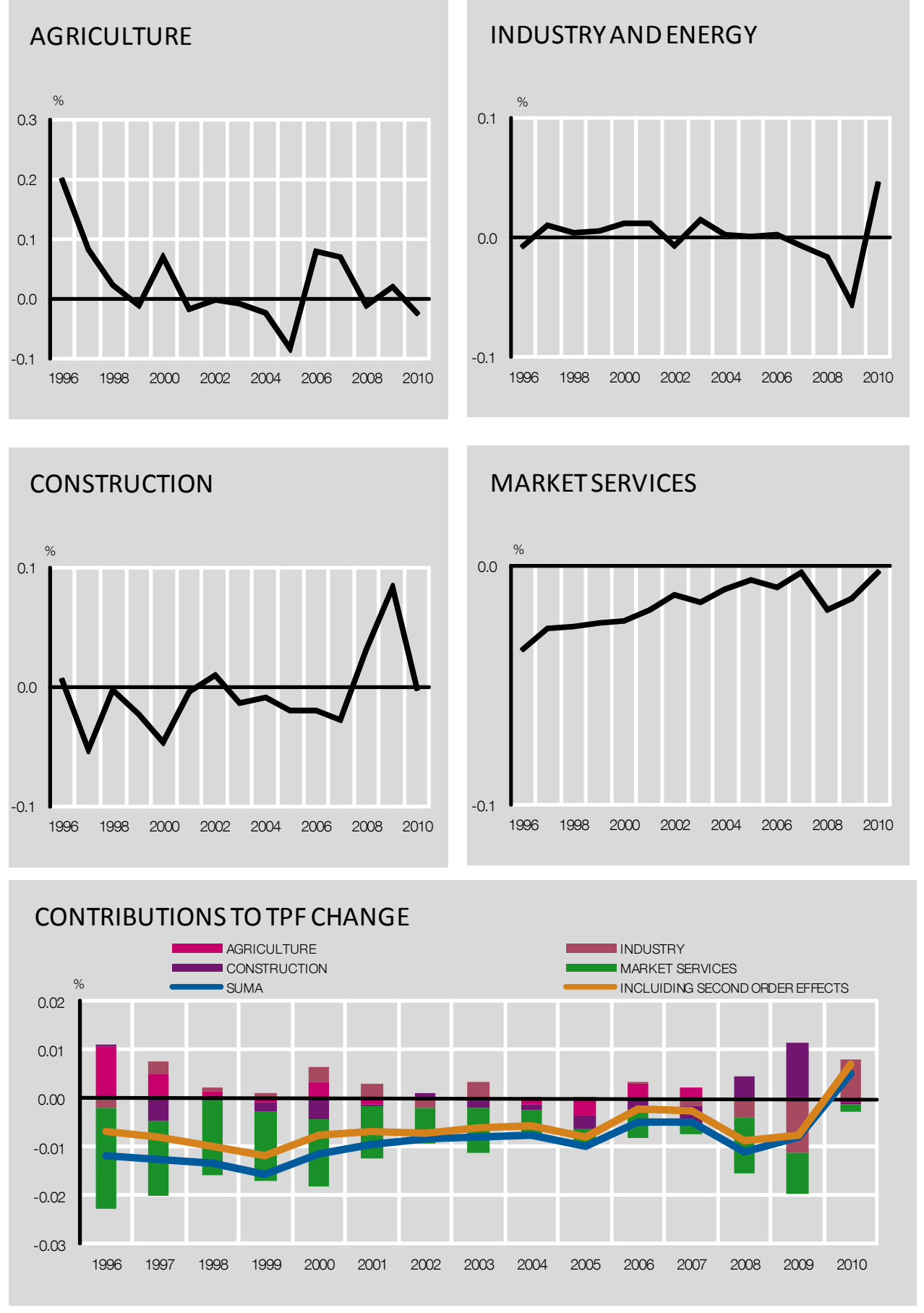

SOURCES: INE and Banco de España.

To try to capture the effect on TFP of sector restructuring, in this paper the TFP forecasts are obtained from the projection of total factor productivity for each sector, for which purpose forecasts of the "Spanish Economic Projections Report" [Banco de España (2011)] until 2012 are used. These essentially assume stabilisation of the growth of this variable in 2010 in construction, agriculture and market services, as well as a certain slowdown towards historic averages in the case of industry. For the period 2013-2015, sectoral TFP growth is assumed to remain constant at its average level in the period 
2010-2012. Also, with regard to the weights used for each sector to calculate the agrregate TFP, it is assumed that the construction sector will continue to lose weight progressively, being offset by the increase in the weight of industry ${ }^{17}$.

The result is a recovery in TFP between 2010 and 2015, which is explained by, in addition to the lower weight of construction, the parallel increase in the weight of industry, which is the sector with the highest rates of productivity growth, and a smaller negative contribution from market services, even though negative TFP growth rates continue to be projected for this sector.

\subsection{Potential output of the non-market sector}

As mentioned above, to obtain the potential output of the economy as a whole, we add to the previously obtained potential output of the market economy, the output of the public sector and indirect taxes net of subsidies. To avoid excessive fluctuations in this variable, the HP filter is used to obtain its trend value (see Chart 15). In the projection period, we assume a fall in the weight of the market economy and therefore a negative contribution by this variable to potential output, which is consistent with the need for fiscal consolidation following the strong growth in the government deficit during the economic crisis (see Chart 15).

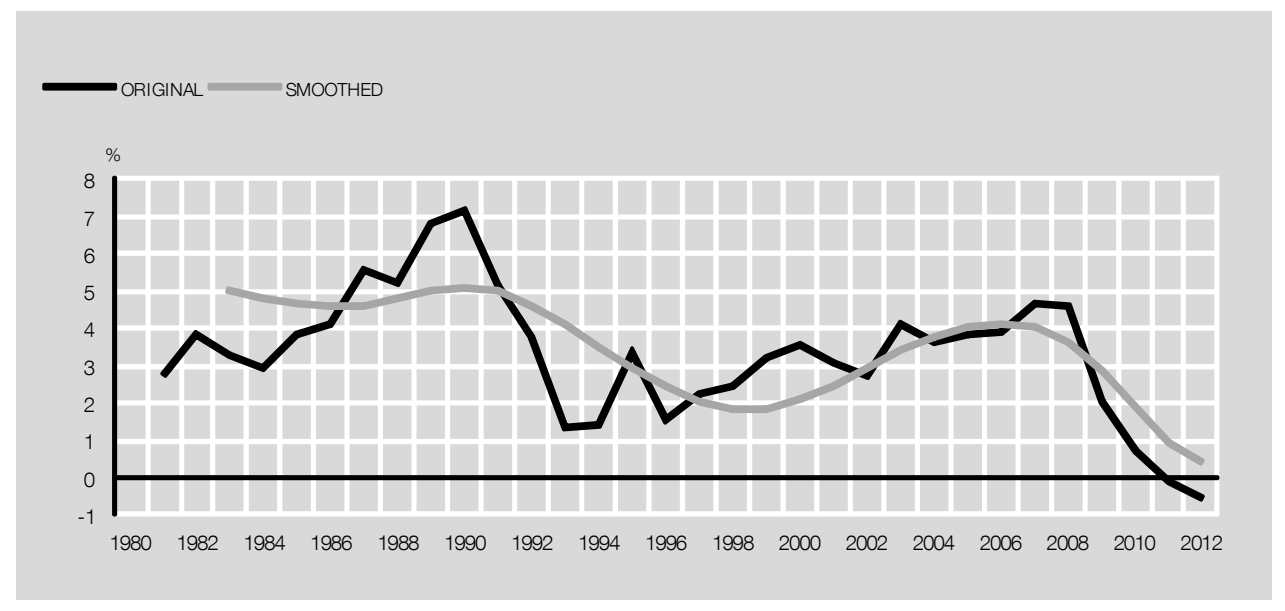

SOURCES: INE and Banco de España

17. The increasing importance of industry to compensate for minor construction is justified because some of the market services are related to housing investment. 
The main results of the estimation of potential output, based on the methodology analysed in the previous sections, are presented below. Three periods are distinguished (see Chart 16): the expansionary phase immediately before the crisis, which spanned the period 2000-2007, the period between 2008 and 2012, covering the years of the economic crisis and immediately after, and the medium-term projection.

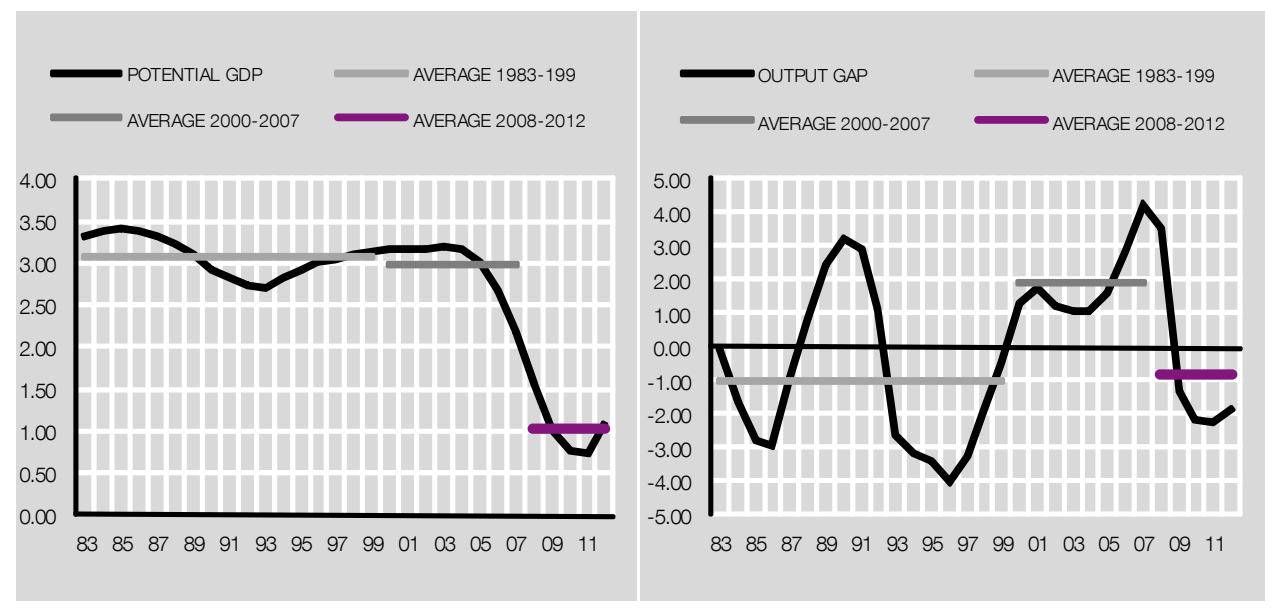

SOURCES: Instituto Nacional de Estadística and Banco de España.

\subsection{The expansionary period (2000-2007)}

The potential growth in GDP of the Spanish economy is estimated to have been around 3\% during the period 2000-2007. This growth rate is basically explained by the highly buoyant behaviour of the factors of production, employment and capital. As seen in Table 1, potential employment grew at an annual average rate of 2.5\% during the period 2005-2007, only slightly below the observed growth in total employment (2.8\% in this period). The growth rate of the potential capital stock stood at $5.1 \%$. Conversely, total factor productivity fell by $0.4 \%$. This average growth was very stable throughout the period considered, although there was a slight slowdown over the period in both employment and capital.

Table 2 shows the contribution of potential employment and its components to the growth of potential output. The increase in potential employment was mainly based on the observed increase in the labour supply, since, even when the cyclical behaviour of this variable during the period is allowed for, the working age population grew by $1.5 \%$ per annum, as a result of the size of the flows of migrants received by the Spanish economy, which raised the percentage of foreigners in the population to about $12 \%$ in 2008 . At the same time, the participation rate increased by $0.7 \mathrm{pp}$ per annum, as a consequence of the positive impact of immigration (immigrants having a higher participation rate than Spanish nationals) and of the notable increase in the female participation rate, which rose by $10 \mathrm{pp}$ between 2001 and 2008, to stand at $64.1 \%$. Also, the sharp reduction in the observed rate of unemployment, which bottomed out in 2007 (8.3\%), after standing at 10.7\% in 2000, was passed through, albeit incompletely, to structural unemployment or NAIRU, 
which stood at $11 \%$ at the end of 2007 . All the determinants of NAIRU mentioned in the previous section contributed to this reduction, in particular the rate of long-term unemployment, which fell to $2 \%$, and female and foreigner participation in the labour force, which rose by 4.0 and 11.3 percentage points, respectively, during this period. Finally, the reduction in hours worked per person slightly moderated the increase in potential employment.

\begin{tabular}{|c|c|c|c|c|c|c|c|c|c|c|}
\hline \multicolumn{11}{|c|}{ Rates of change (unless otherwise indicated) in the potential variables } \\
\hline & $\begin{array}{c}\text { Average } \\
2000-2007\end{array}$ & $\begin{array}{l}\text { Average } \\
\text { 2008-2012 }\end{array}$ & 2000 & 2001 & 2002 & 2003 & 2004 & 2005 & 2006 & 2007 \\
\hline \multicolumn{11}{|l|}{ NAIRU } \\
\hline POTENTIAL GROWTH & 3.0 & 1.0 & 3.2 & 3.2 & 3.2 & 3.2 & 3.2 & 3.0 & 2.7 & 2.2 \\
\hline WEIGHT OF THE NON-MARKET ECONOMY & (a) 0.1 & 0.2 & -0.2 & -0.1 & 0.0 & 0.0 & 0.1 & 0.2 & 0.3 & 0.3 \\
\hline EMPLOYMENT & 2.5 & 0.8 & 2.5 & 2.7 & 2.7 & 2.6 & 2.5 & 2.5 & 2.4 & 2.3 \\
\hline HOURS WORKED PER PERSON & -0.7 & 0.0 & -0.3 & -0.5 & -0.7 & -0.9 & -1.0 & -1.0 & -0.8 & -0.6 \\
\hline PERSONS & 3.0 & 1.3 & 2.6 & 2.8 & 2.9 & 2.9 & 3.0 & 3.1 & 3.3 & 3.3 \\
\hline POPULATION AGED 15-64 & 1.5 & 0.4 & 1.0 & 1.2 & 1.5 & 1.6 & 1.7 & 1.7 & 1.6 & 1.4 \\
\hline PARTICIPATION RATE (a) & 0.7 & 0.4 & 0.7 & 0.7 & 0.7 & 0.7 & 0.7 & 0.7 & 0.6 & 0.6 \\
\hline NAIRU (a) & -0.2 & 0.9 & -0.4 & -0.3 & -0.3 & -0.4 & -0.3 & -0.2 & 0.1 & 0.5 \\
\hline CAPITAL & 5.1 & 3.0 & 5.5 & 5.4 & 5.3 & 5.1 & 5.0 & 4.9 & 4.7 & 4.4 \\
\hline TFP & -0.4 & -0.2 & -0.4 & -0.4 & -0.4 & -0.4 & -0.4 & -0.4 & -0.4 & -0.5 \\
\hline
\end{tabular}

(a) Level difference in percentage points.

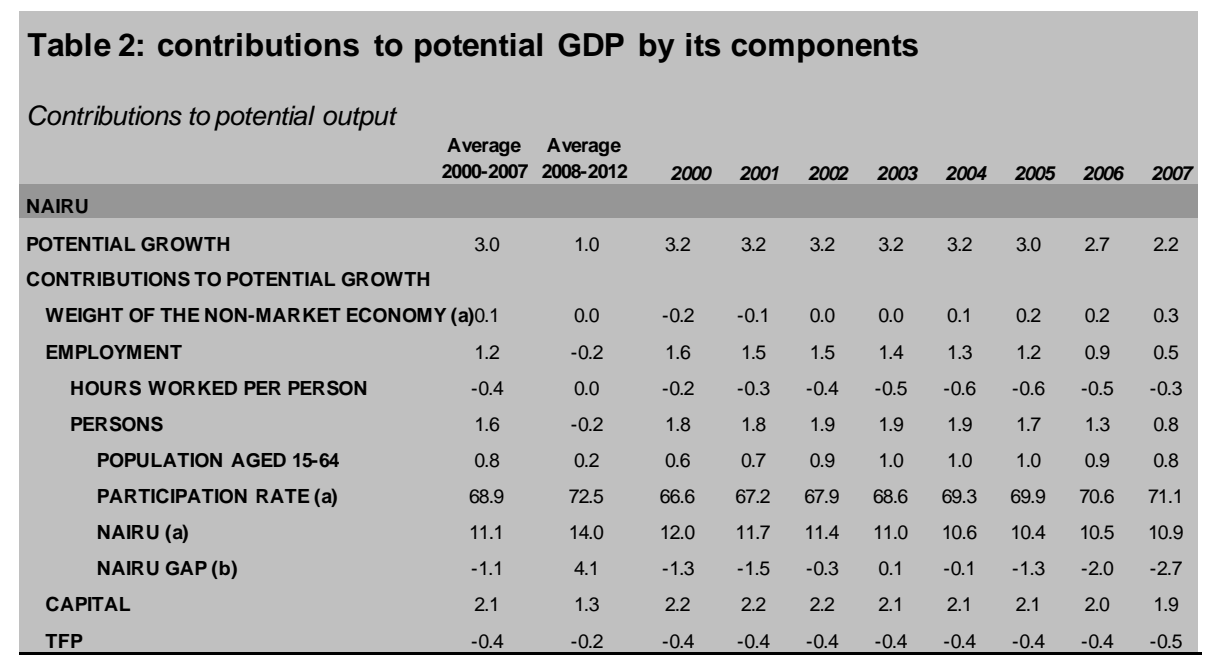

(a) Series in levels.

(b) Percentage difference between the actual and the potential rate of unemployment.

With regard to the contribution by the capital stock, it should be noted that one of the features of the Spanish economy during the expansionary period was the high growth in investment, in particular in the construction and housing sectors, but also in market services and in industry and energy. There are various arguments to explain this investment boom, including the decline in interest rates and the sharp increase in labour supply, which reduced the capital/labour ratio and led to an increase in capital productivity. In fact the rate of investment, which stood at around $22 \%$ in the mid-1990s, reached nearly 30\% in 2006 and 2007 (see Chart 17). 
As a result of this investment effort, and having corrected for the relative user cost of the different types of capital stock considered, there was an increase in this period in the contribution of capital to potential growth. As seen in Chart 18, the largest contribution to the capital stock was made by the market services sector (which explains almost half of the total increase in capital), followed by non-market services, housing, industry and energy and finally construction and agriculture. In all, capital contributed somewhat more than two percentage points to the growth in the potential output of the Spanish economy in the period 2000-2007.

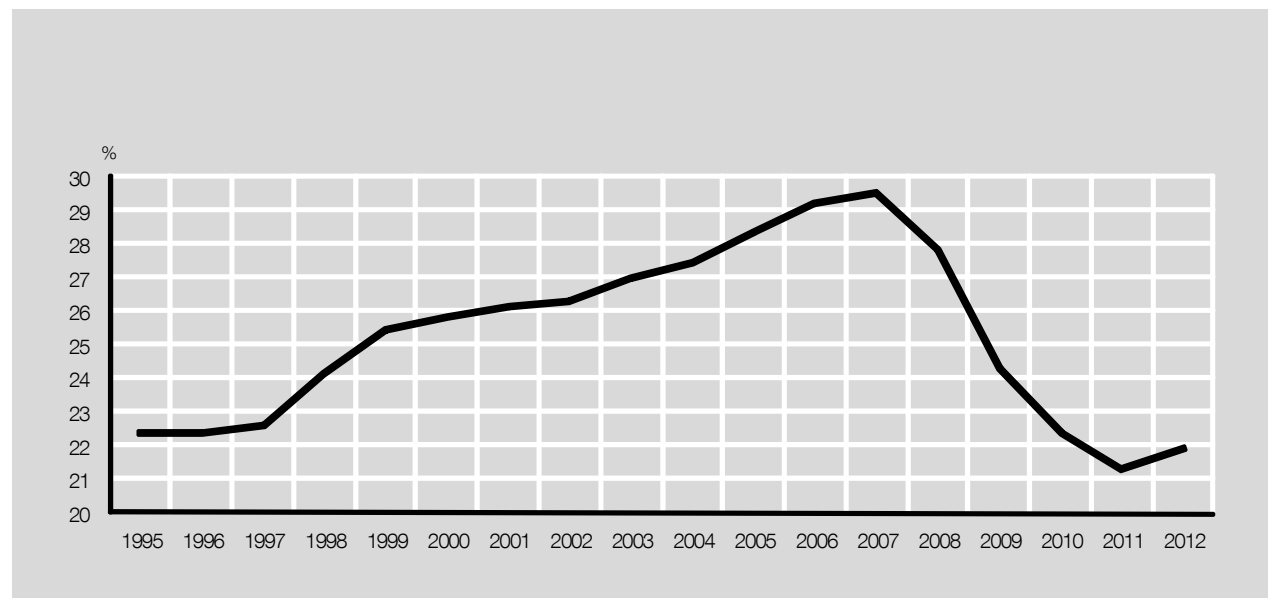

SOURCE: Instituto Nacional de Estadística.

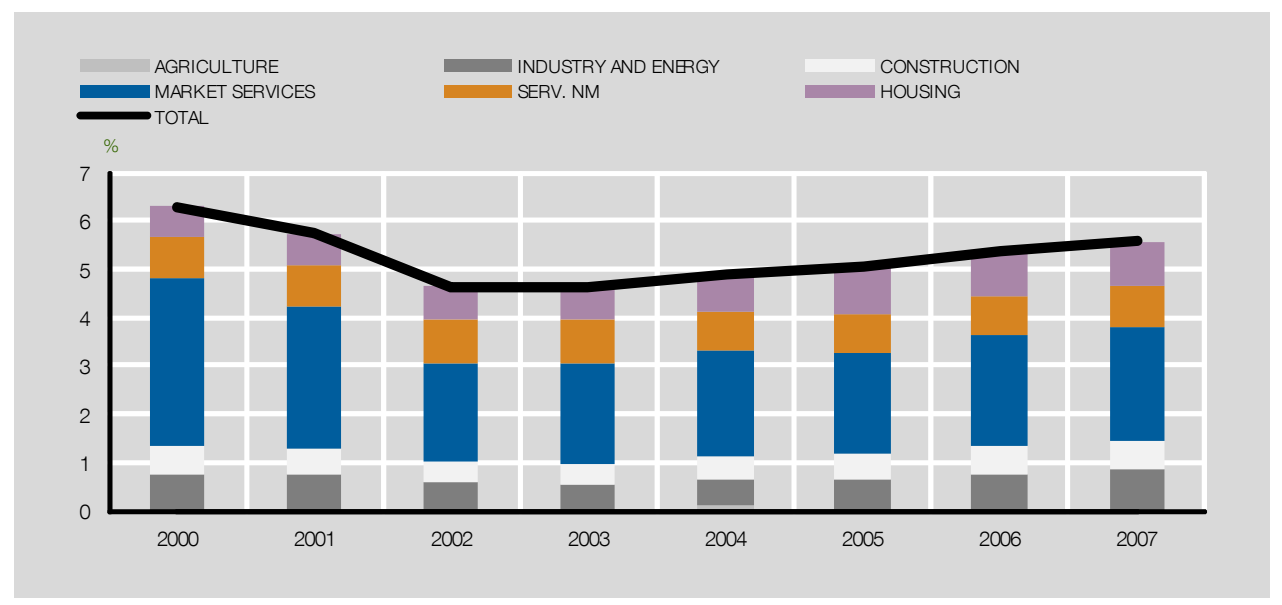

SOURCE: EUKLEMS.

With regard to TFP, one of the most striking features of the evolution of the Spanish economy prior to the crisis was that the high growth in the factors of production, and thus in their contributions to potential output, was accompanied by a slowdown in total factor productivity. TFP even recorded negative growth rates from 2000, thereby contributing to reducing potential output growth (its average contribution was $-0.4 \mathrm{pp}$ ). 
The sectoral composition of growth during the expansionary phase explains only part of the unfavourable behaviour of TFP. In particular, the gain in weight of the construction sector, which displays negative TFP growth rates throughout the period, along with the fact that falls in total factor productivity were also seen in market services, would explain virtually the entire slowdown in TFP.

\subsection{The period from 2008 to 2012}

As mentioned in the introduction, the economic crisis has had a negative effect on the level of potential output through various channels such as, for example, the fall in investment and the increase in the rate of structural unemployment. This impact on the level of potential output is reflected in our estimates in the form of slower growth of this variable during the crisis and immediately thereafter, since some of these effects occur with a certain lag. In particular, as seen in Table 3, the potential output of the Spanish economy appears to have decelerated significantly, from rates of close to $3 \%$ between 2000 and 2007 to rates of around $1 \%$ in the period 2008-2012.

\begin{tabular}{|c|c|c|c|c|c|c|c|}
\hline & $\begin{array}{c}\text { Average } \\
2000-2007\end{array}$ & $\begin{array}{l}\text { Average } \\
2008-2012\end{array}$ & 2008 & 2009 & 2010 & 2011 & 2012 \\
\hline \multicolumn{8}{|l|}{ NAIRU } \\
\hline POTENTIAL GROWTH & 3.0 & 1.0 & 1.6 & 1.0 & 0.8 & 0.8 & 1.1 \\
\hline WEIGHT OF THE NON-MARKET ECONOMY (a) & 0.1 & 0.2 & 0.4 & 0.4 & 0.2 & 0.0 & -0.1 \\
\hline EMPLOYMENT & 2.5 & 0.8 & 2.0 & 1.5 & 0.9 & 0.1 & -0.5 \\
\hline HOURS WORKED PER PERSON & -0.7 & 0.0 & -0.2 & 0.0 & 0.1 & 0.0 & -0.1 \\
\hline PERSONS & 3.0 & 1.3 & 3.0 & 2.4 & 1.4 & 0.4 & -0.6 \\
\hline POPULATION AGED 15-64 & 1.5 & 0.4 & 1.0 & 0.6 & 0.3 & 0.0 & -0.1 \\
\hline PARTICIPATION RATE (a) & 0.7 & 0.4 & 0.5 & 0.5 & 0.5 & 0.3 & 0.4 \\
\hline NAIRU (a) & -0.2 & 0.9 & 0.9 & 1.2 & 1.2 & 0.9 & 0.5 \\
\hline CAPITAL & 5.1 & 3.0 & 3.9 & 3.3 & 2.8 & 2.5 & 2.4 \\
\hline TFP & -0.4 & -0.2 & -0.5 & -0.4 & -0.2 & 0.0 & 0.3 \\
\hline
\end{tabular}

(a) Level difference in percentage points.

Especially striking is the negative contribution of potential employment (see Table 4), following the sharp increases in the expansionary period. First, the impact of the economic crisis on the supply of labour has been notable, primarily as a consequence of the slowdown in migratory flows which, according to INE estimates slowed sharply from mid-2008, to reach negative rates in 2011 Q1. This sensitivity to the economic situation has been seen both in the case of inflows, which fell from around 80,000-100,000 persons per month at the beginning of 2007 to around 40,000 in 2009 and 2010 (37.000 people per month in 2011 Q1), and in the case of outflows, which rose to levels of 35,000 per month in 2009 and 2010 and 45,000 people per month in 2011 Q1, from levels of around 20,000 previously ${ }^{18}$. Indeed, net migratory flows were negative in the first quarter of 2011. As a result, and having allowed for the cyclical component of this slowdown, the contribution to potential output made by the working age population is estimated to have fallen from $0.8 \%$ in the previous period to $0.2 \%$ in this period.

18. In general, the elasticity of migratory flows to changes in GDP would be in line with the estimate in Lacuesta and Puente (2009) in the case of inflows and may be somewhat higher in that of outflows. 


\begin{tabular}{|c|c|c|c|c|c|c|c|}
\hline $\begin{array}{l}\text { Table 4: contributions to } \\
\text { Contributions to potential output }\end{array}$ & $\begin{array}{l}\text { potent } \\
\text { Average } \\
2000-2007\end{array}$ & $\begin{array}{c}\text { Average } \\
2008-2012\end{array}$ & by & S C & 2010 & 2011 & 2012 \\
\hline \multicolumn{8}{|l|}{ NAIRU } \\
\hline POTENTIAL GROWTH & 3.0 & 1.0 & 1.6 & 1.0 & 0.8 & 0.8 & 1.1 \\
\hline \multicolumn{8}{|l|}{ CONTRIBUTIONSTO POTENTIAL GROWTH } \\
\hline WEIGHT OF THE NON-MARKET ECONOMY (a) & 0.1 & 0.2 & 0.3 & 0.3 & 0.2 & 0.0 & -0.1 \\
\hline EMPLOYMENT & 1.2 & -0.2 & 0.1 & -0.3 & -0.4 & -0.4 & -0.1 \\
\hline HOURSWORKED PER PERSON & -0.4 & 0.0 & -0.1 & 0.0 & 0.1 & 0.0 & 0.0 \\
\hline PERSONS & 1.6 & -0.2 & 0.2 & -0.3 & -0.5 & -0.4 & -0.4 \\
\hline POPULATION AGED 15-64 & 0.8 & 0.2 & 0.6 & 0.4 & 0.2 & 0.0 & 0.0 \\
\hline PARTICIPATIONRATE(a) & 68.9 & 72.5 & 71.6 & 72.1 & 72.6 & 72.9 & 72.9 \\
\hline NAIRU (a) & 11.1 & 14.0 & 11.8 & 13.0 & 14.2 & 15.1 & 15.1 \\
\hline NAIRU GAP (b) & -1.1 & 4.1 & -0.5 & 5.0 & 5.9 & 5.6 & 5.6 \\
\hline CAPITAL & 2.1 & 1.3 & 1.7 & 1.5 & 1.3 & 1.1 & 1.1 \\
\hline TFP & -0.4 & -0.2 & -0.5 & -0.4 & -0.2 & 0.0 & 0.0 \\
\hline
\end{tabular}

(a) Series in levels.

(b) Percentage difference between the actual and the potential rate of unemployment.

With regard to the labour market participation, a slowdown in the increase in the participation rate began to be observed from mid-2009, and the rate even began to fall in the case of Spanish men. Among Spanish women, there have been declines in the participation rates of the youngest women, who may, like men, be extending their training given the poorer prospects in the labour market ${ }^{19}$. At intermediate and higher ages, however, Spanish women continue to record large increases in their participation rates, which may be related to a still significant cohort effect. In general, the negative response of this variable to the increase in unemployment is proving to be smaller now than in previous recessions [see Montero (2011)]20. In any case, in terms of potential participation, the deterioration in labour market conditions is estimated to have slowed down the rise in the participation rate during these years, leading, depending on the estimated NAIRU, to year-on-year rises of 0.3 pp to 0.5 pp per annum in the period 2008-2012, which although positive are lower than those seen between 2001 and 2007.

With regard to NAIRU, its estimation reaches levels of around 15\% in 2012, four percentage points up from 2007, which is a significant increase, but well below the observed and projected increase of almost 12 percentage points in the unemployment rate during the same period. According to this estimate, around 1/3 of the rise in unemployment was passed through to structural unemployment. As for its determinants, the rate of long-term unemployment rose significantly, although it is still below the levels seen in the recession in the early $1990 \mathrm{~s}^{21}$. In any event, the incidence of long-term unemployment more than doubled to $46.6 \%$ of total unemployment in 2011 Q1. Likewise, although at the start of the crisis the increase in unemployment seemed to be primarily related to a very considerable increase in flows out of employment, subsequently there has also been a significant fall in flows out of unemployment (see Chart 19).

19. It is interesting to note that, according to LFS micro data, the probability of an economically inactive young person commencing studies stood at $17.8 \%$ in 2010 Q3, up more than 3 pp from the same quarter a year earlier, and remained at elevated levels afterwards.

20. In fact, the estimated coefficient of response of the participation rate to unemployment described in Section 2 is half the one when the data on which it is based doesn't include the latest period.

21. The average rate of long-term unemployment in the period 1991-94 was 10.5\%, whereas in 2011 Q1 it stood at $10 \%$. 


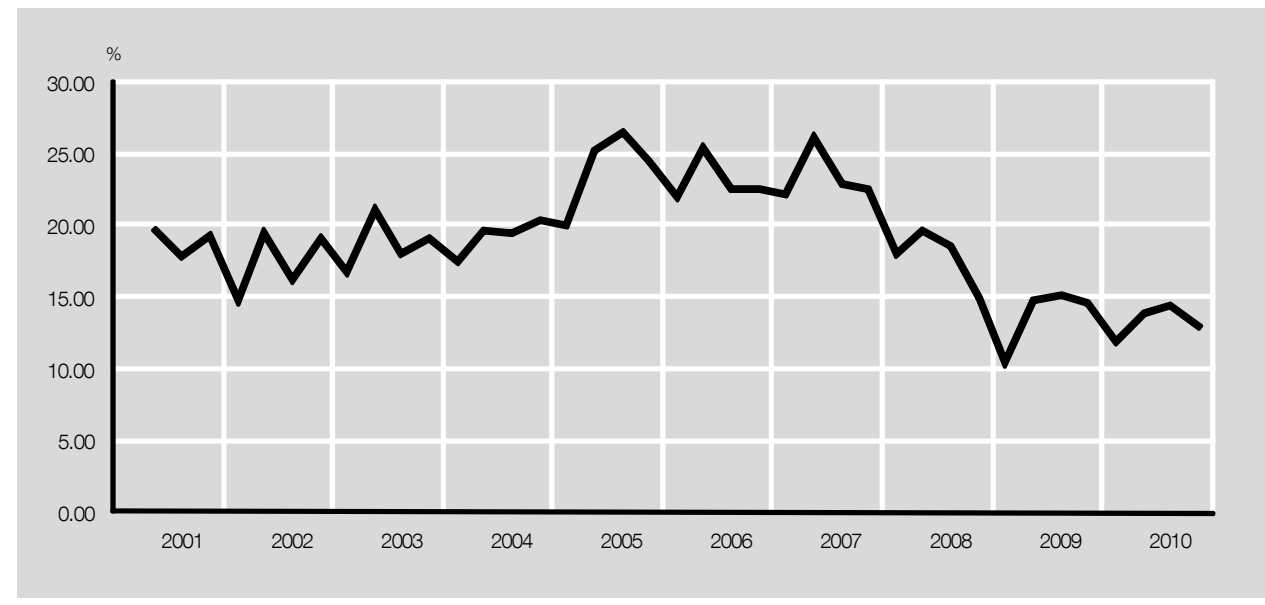

SOURCE: Instituto Nacional de Estadística and Banco de España.

As a result, as seen in Chart 20, the unemployment gap would reach higher levels in this crisis than in the recession in the early 1990s. Overall, therefore, the contribution of employment to growth in potential output falls from positive levels of around 1.5 percentage points to negative levels of around 0.2 percentage points over the period 2008-2012.

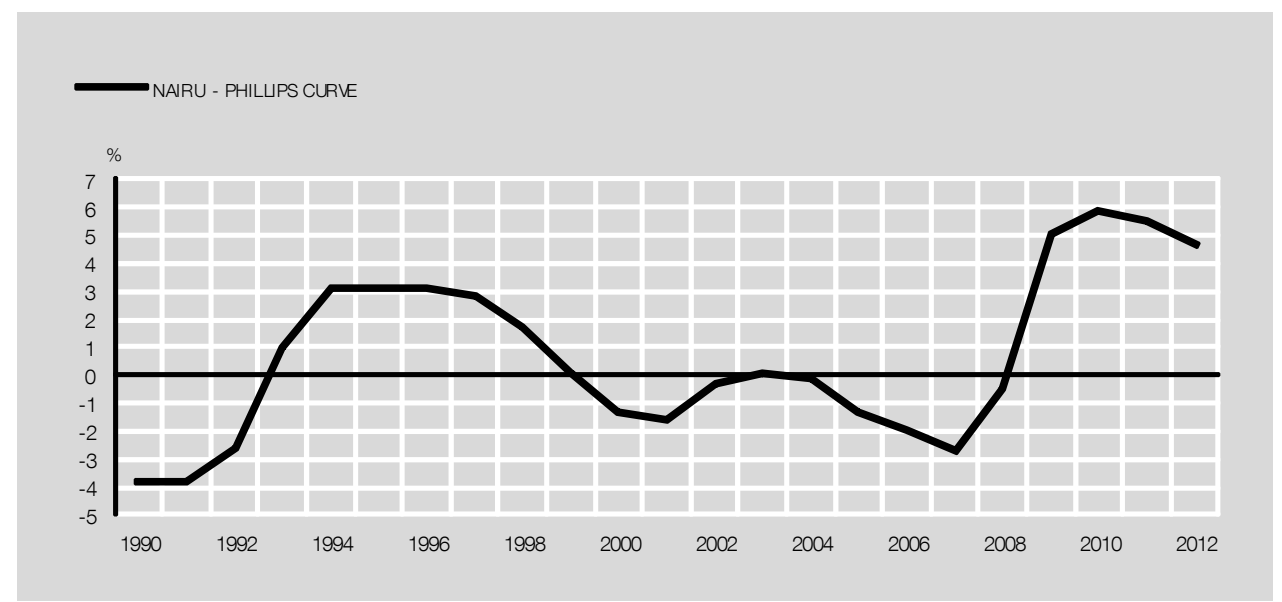

SOURCE: Banco de España.

The economic crisis has also had a very negative effect on investment. Indeed, the fact that the nature of the economic crisis is, at least in part, financial and that, in the short term, investment is the most sensitive macroeconomic aggregate to financial conditions means that the effect of the crisis on this variable in the short term is very significant. In addition, in the case of Spain, this period was preceded by excessive residential 
investment ${ }^{22}$. Indeed, the impact is proving particularly large in the case of housing investment which, given the relative costs of capital, limits the impact on the capital stock. In any event, the contribution of the capital stock to potential growth is estimated to fall by somewhat more than half a percentage point in the period 2008-2012 from the contribution estimated for the previous period.

That said, the impact of the crisis on the capital stock could be even larger than estimated, since the destruction of the productive capital stock resulting from the disappearance of firms, which has been especially severe during the crisis, has not been taken into account. According to some estimates [see, for example, Banco de España (2010)], the closure of firms generated an increase in the destruction of installed capacity in 2008 and 2009, with respect to 2007, of between 0.7 and 2.0 pp per annum, which would be equivalent in both cases to a temporary increase of similar magnitude in the rate of depreciation of aggregate capital.

Finally, with regard to TFP, the sectoral restructuring that is taking place and that is expected to continue in coming years, will have had a positive effect on this variable, whose contribution may be progressively less negative and even become zero in 2011 and 2012. As indicated in the previous section, the fall in TFP during the expansionary phase occurred partly as a consequence of the increase in the weight of the construction sector. Accordingly, as the weight of this activity returns to a lower level one would expect productivity to display an improvement. It should be borne in mind that the projection for 2011 and 2012 assumes a stabilization of the TFP in the service sector in its recent levels, which has also been higher between 2008 and 2010 than in the previous expansion period. In any event, the observed increase in hours worked per worker during the crisis would have limited the recovery of this variable.

Finally, with regard to the contribution of the non-market sector, in 2008 and 2009 the expansionary fiscal policy measures applied will have involved a significant increase in this contribution, which will be reversed in subsequent years as a consequence of the application of the fiscal adjustment plans necessary to return public finances to a sound footing.

The crisis had a strong negative impact on the Spanish economy, which in the case of the estimates of potential output extends this impact to the years immediately after the crisis given that some of the negative effects only appear after a certain time lag. Overall, the potential output growth of the Spanish economy is estimated to have been close to 3\% in 2000-2007 and around 1\% between 2008 and 2012. Given these potential output growth estimates and the GDP growth projections included in Banco de España (2011), the output gap can be estimated. In particular, it is estimated that the output gap declined significantly since 2007 to reach progressively higher negative levels in 2009 and 2010 (see Chart 16). In 2011 the output gap would remain around 2\%, while it would start closing in 2012, given that the projected real GDP growth is higher than the estimated potential output growth for that year.

It is difficult to quantify precisely what has been the cost in terms of potential output loss because an estimate of this kind would require knowing what would have been

22. Although national accounting rules mean that the expenditure necessary to construct such housing should not form part of gross fixed capital formation, but be included in changes in inventories, the absence of reliable information prevents this, so that when gross fixed capital formation is accumulated, the capital stock taken as the starting point for the projection exercise is overvalued. 
the evolution in the case of non-negative shocks have occurred that have led to this recession. To illustrate, Chart 21 shows the comparison of the potential output estimated in this paper (which we call, observed) with the one assuming that the potential growth had continued to grow at the same rate as before the crisis. The result of this comparison shows a loss of potential output of around $4 \%$.

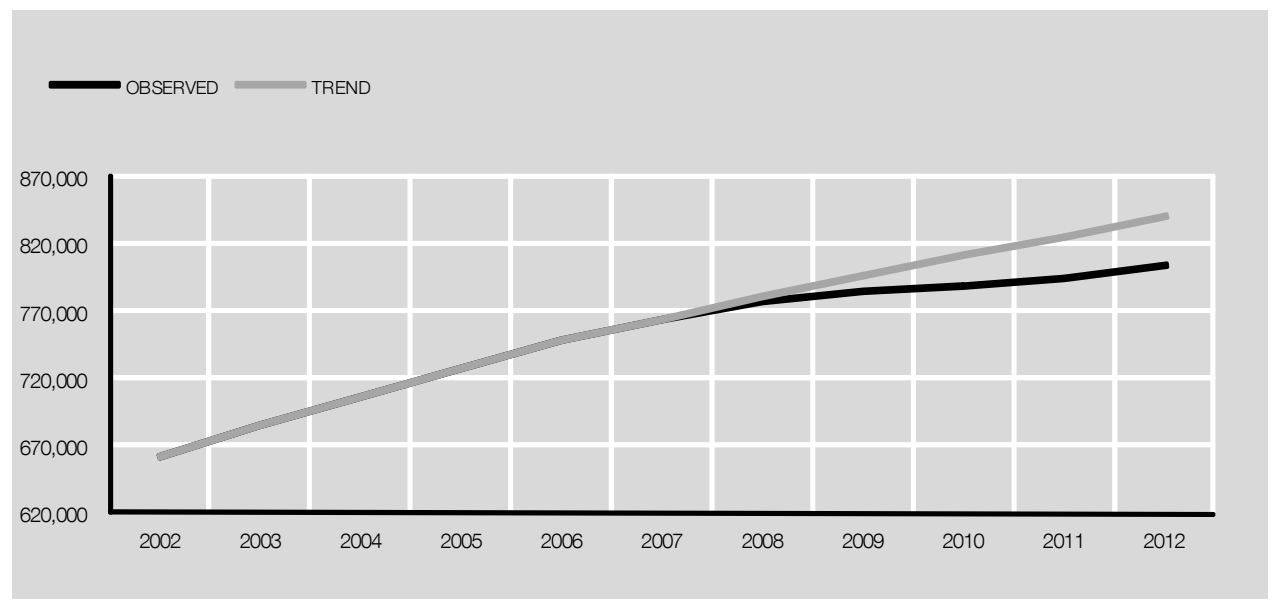

SOURCE: Banco de España.

\subsection{The medium term}

As mentioned in the introduction, consideration of a medium-term horizon in estimating the potential growth of the economy is especially important in the current situation because the impact of the crisis on the level of potential output is reflected in our estimates in a lower growth for this variable during the years of crisis and in the immediate aftermath, to the extent that some of these effects occur at a certain time lag. Therefore, the estimates presented in the previous section for 2008-2012 cannot be taken as a projection of the growth rate of potential output of the economy in the medium and long term. For the latter, it is necessary an estimate for the projection period in the long run, when the effects of the economic crisis on the level of potential output have dissipated.

However, this estimate of the medium term requires taking a number of assumptions about the behavior of the economy, which is especially difficult since there are no available macroeconomic projections so distant in time. The results are therefore subject to these assumptions, which in our case have been detailed along the second section of this paper and summarized below:

- First, it should be noted that the potential impact of certain structural reforms is not incorporated, which in case of being implemented, could significantly improve the growth potential of the economy.

- We use the population projections through 2015 of INE, which implies a decline of working age population in the coming years, which will become one of the major drivers of growth of the Spanish economy, as in other developed economies. 
- The potential participation rate is projected including the estimated cohort effect for women as well as those derived from a more educated population, which are of a smaller magnitude compared to those seen in the last decade.

- The projected evolution of the unemployment rate up to 2015 is similar to the one observed at the end of the 1993 recession, resulting in a NAIRU that, after reaching its peak in 2011 and 2012, would be reduced later.

- It is assumed that real interest rates will not return to the low levels observed prior to the stage immediately preceding the crisis, but to be at a higher level, similar to those observed between 1996 and 1999. Under this assumption and using the quarterly model of the Bank of Spain (MTBE) investment is projected to follow a similar evolution to that in the years following the recession of the 90s.

- With regard to TFP growth, it is assumed that the growth rate of this variable, at the sectoral level, is held constant at the average growth rate of the 2010-2012 period, while it is also assumed that the construction will continue to lose weight gradually, and be offset by an increase in the industry sector.

- The evolution of the non-market economy will be conditioned by fiscal consolidation, which requires reaching a deficit of $3 \%$ in 2013 and then a gradual move towards a balanced budget.

As a result, in the medium term our estimates show a certain recovery in the growth rate of the Spanish economy's potential output, when the effects of the economic crisis on the level of this variable have dissipated. Medium-term growth is estimated to stand at around $2 \%$ in 2015 , that is to say one percentage point lower than the rate in the expansionary period prior to the crisis. Specifically, the estimated contribution of each of the productive factors (labour and capital) in 2015 is almost 1.6 percentage points lower than their estimated contributions between 2000 and 2007, which is partly offset by a greater contribution from TFP (see Chart 13).

These estimates are in line with those recently published by the Ministry of Economy and Finance in the Informe sobre posición cíclica de la economía española published on 6 April 2011, which provides estimates of potential output through 201423. In the same vein, the OECD (2009) estimates the potential growth rate of the Spanish economy at around $2.1 \%$ for the period 2011-2017, while those of the IMF (2011) are close to $1.7 \%$ for the year 2016 .

As to potential employment, different factors lie behind our results. First, the latest population projections prepared by INE anticipate a further slowdown in migratory flows, which would lead to a fall in the working age population in the next years. This is one of the most important factors behind our potential output growth projections. Thus, the contribution of population to potential output growth falls to $-0.1 \%$ in the period $2013-2015$, almost one percentage point down from the estimate for 2000-2007. Indeed, as can be seen in chart 22, in per capita terms potential growth is estimated to be similar to the one observed in the expansionary period previous to the crisis.

23. In particular, according to the estimates of the Ministry of Finance potential output growth will reach $1.7 \%$ in 2014 (see http://www.meh.es/Documentacion/Publico/GabineteMinistro/Varios/InformePosicionCiclica2011.pdf). 


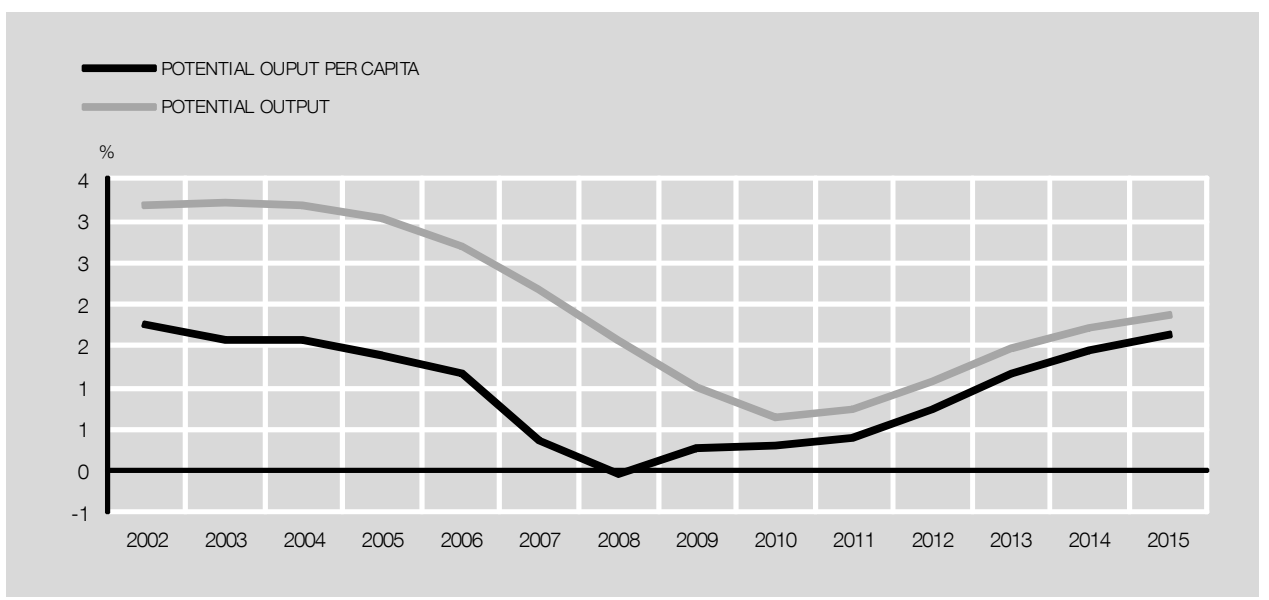

As for the participation rate, the existence of a still significant cohort effect enables a positive contribution to be made by this variable, although the progressive dissipation of this effect and the smaller estimated immigration flows reduce the annual change in the potential participation rate to half the level estimated for the period 2000-2007, to 0.4 pp in 2015 . In relation to the NAIRU, the estimation assumes only a slight reduction in this variable in the medium term, in contrast to the significant fall in the expansionary period. As a result of all these factors, the contribution of employment to potential output falls from $1.2 \mathrm{pp}$ in the period 2000-2007 to $0.5 \mathrm{pp}$ in 2015.

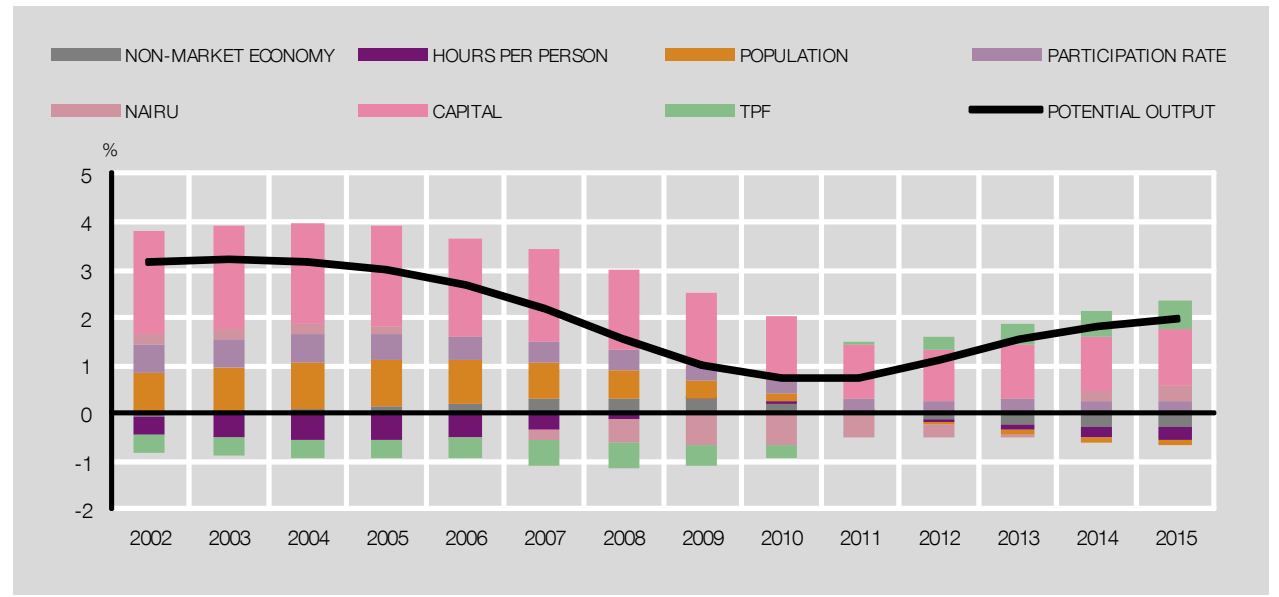

SOURCE: Banco de España.

With regard to the capital stock, after 2012 the assumptions made regarding the evolution of the capital/employment ratio cause, as seen in Chart 23, the capital stock/output ratio of the private sector to converge smoothly to levels around $5.6 \%$, as compared with the level of $4.6 \%$ reached just before the recession. In this scenario, the contribution of the capital stock to the economy's potential output stands at around one percentage point from 2012. 
With respect to total factor productivity, both the convergence of the weight of construction on more comparable levels with other development countries and the stabilisation of productivity growth in the market services sector, as well as the higher weight of the industrial sector, result in a positive contribution to potential output growth. Specifically, the contribution of TFP to potential output is about half a percentage point in the period 2013-2015, clearly higher than during the past decade. These increases in TFP are in line with those observed in the years following the crisis in the early 1990s (see Chart 12). Finally, the contribution of the public sector becomes negative as a consequence of the fiscal consolidation process. 


\section{Conclusions}

This paper seeks to estimate the potential output of the Spanish economy, using the production function methodology standard in the literature, albeit with certain modifications to reflect some specific features of the Spanish economy. The basic advantage of this methodology, over purely statistical methods, is that it enables the determinants of potential growth to be analysed.

It is important to point out, however, that the estimation of potential output is subject to a high degree of uncertainty, since a very broad set of information is required and a considerable number of simplifying assumptions must be made. This uncertainty is especially high in an environment like the current one, in which it is difficult to determine the extent of the effects of the economic crisis on the level of potential output and also on its future growth rate.

According to the methodology proposed in this paper, the growth of the potential output of the Spanish economy stood at around 3\% in the period 2000-2007, owing to the marked increase in the population and in the participation rate and the fall in structural unemployment, as well as vigorous capital accumulation. The contribution of these factors to potential output was reduced by the negative evolution of total factor productivity.

The economic crisis is estimated to have had a significant negative impact on potential output, which has primarily taken the form of a large increase in structural unemployment, a sharp slowdown in population growth, as a consequence of the loss of momentum in immigrant inflows, and a reduction in the contribution of the capital stock resulting from the impact of the crisis on investment. As a result, the potential growth of the Spanish economy stands at around 1\% during the crisis years and in the years immediately thereafter, insofar as some of these negative effects take place with a certain time lag.

Lastly, in the medium term, the potential output of the economy is estimated to recover progressively, once the effects of the crisis have disappeared, reaching growth rates about $2 \%$ in 2015, against a background of negative rates of change in the population of age 16-64, accordingly with the latest projections of INE, a smooth improvement in the NAIRU and a slight recovery in investment, and a higher contribution from TFP. The application of a strong process of structural reforms could, however, significantly improve the growth prospects of our economy [Gavilán et al. (2011)]. 


\section{REFERENCES}

CuAdRAdo, P., A. LACUESTA, J. M. MARTínEZ y E. PÉREZ (2007). El futuro de la tasa de actividad española: un enfoque generacional, Documentos de Trabajo, No. 0732, Banco de España.

BANCO DE ESPAÑA (2010). Annual Report, 2009, Box 2.1 «Business closures in Spain during the economic crisis».

— (2011). «Spanish Economic Projections Report», Economic Bulletin, April, pp. 71-85.

BENTOLILA, S., J. J. DOLADO y J. F. JIMENO (2008). «Does immigration affect the Phillips curve? Some evidence for Spain", European Economic Review, 52, 8, pp. 1398-1425.

ESTRADA, Á., P. HERNÁNDEZ DE COS y J. JAREÑO (2004). Una estimación del crecimiento potencial de la economía española, Documentos Ocasionales, No. 0405, Banco de España.

ESTRADA, Á., I. HERNANDO y D. LÓPEZ SALIDO (2002). "La medición de la NAIRU en la economía española», Moneda y Crédito, No. 215, pp. 69-107.

IMF (2011). World Economic Outlook, April 2011.

GAVILÁN, A., P. HERNÁNDEZ DE COS, J. F. JIMENO y J. A. ROJAS (2011). Fiscal policy, structural reforms and external imbalances: a quantitative evaluation for Spain, Documentos de Trabajo, No. 1107, Banco de España.

HULTEN, C. R., y F. C. WYCKOFF (1981a). "The estimate of economic depreciation using vintage asset prices», Journal of Econometrics, 15, pp. 367-396.

- (1981b). «The Measurement of Economic Depreciation», in C. R. Hulten (ed.), Depreciation, Inflation and the Taxation of Income from Capital, The Urban Institute Press, Washington, DC.

HURTADO, S., E. FERNÁNDEZ, E. ORTEGA y A. URTASUN (2011). Actualización del modelo trimestral del Banco de España, Documento Ocasional, forthcoming, Banco de España.

IZQUIERDO, M., y J. JAREÑO (2007). «Estimates of the potential growth rate of the spanish economy», Economic Bulletin, January, pp. 101-105.

LACUESTA, A., y S. PUENTE (2010). El efecto del ciclo económico en las entradas y salidas de inmigrantes en España, Documentos de Trabajo, No. 1016, Banco de España.

LACUESTA, A., S. PUENTE y P. CUADRADO (2007). «Una aproximación a la medición de la calidad del factor trabajo en España», Boletín Económico, January, Banco de España, pp. 81-87.

MINISTERIO DE ECONOMÍA Y HACIENDA (2011). Informe sobre la posición cíclica de la economía española, 6 April.

MONTERO, J. M. (2011). «El comportamiento de la tasa de actividad durante la última fase recesiva", Boletín Económico, April, Banco de España, pp. 87-97.

OCDE (2009). «Beyond the crisis: medium-term challenges relating to potential output, unemployment and fiscal positions", Chapter 4, OECD Economic Outlook, No. 85.

O'MAHONY, M., and M. P. TIMMER (2009). «Output, Input and Productivity Measures at the Industry Level: the EU KLEMS Database», The Economic Journal, 119, June, pp. F374-F403. 


\section{BANCO DE ESPAÑA PUBLICATIONS}

\section{OCCASIONAL PAPERS}

0501 JOSÉ RAMÓN MARTÍNEZ-RESANO: Size and heterogeneity matter. A microstructure-based analysis of regulation of secondary markets for government bonds.

0502 ALICIA GARCÍA-HERRERO, SERGIO GAVILÁ AND DANIEL SANTABÁRBARA: China's banking reform: an assessment of its evolution and possible impact.

0503 ANA BUISÁN, DAVID LEARMONTH AND MARÍA SEBASTIÁ BARRIEL: An industry approach to understanding export performance: stylised facts and empirical estimation.

0504 ANA BUISÁN AND FERNANDO RESTOY: Cross-country macroeconometric heterogeneity in EMU.

0505 JOSÉ LUIS MALO DE MOLINA: Una larga fase de expansión de la economía española.

0506 VÍCTOR GARCÍA-VAQUERO AND JORGE MARTÍNEZ: Fiscalidad de la vivienda en España.

0507 JAIME CARUANA: Monetary policy, financial stability and asset prices.

0601 JUAN F. JIMENO, JUAN A. ROJAS AND SERGIO PUENTE: Modelling the impact of aging on Social Security expenditures.

0602 PABLO MARTÍN-ACEÑA: La Banque de France, la BRI et la création du Service des Études de la Banque d’Espagne au début des années 1930. (There is a Spanish version of this edition with the same number.)

0603 CRISTINA BARCELÓ: Imputation of the 2002 wave of the Spanish Survey of Household Finances (EFF).

0604 RAFAEL GÓMEZ AND PABLO HERNÁNDEZ DE COS: The importance of being mature: The effect of demographic maturation on global per-capita income.

0605 JUAN RUIZ AND JOSEP VILARRUBIA: International recycling of petrodollars. (The original Spanish version has the same number.)

0606 ALICIA GARCÍA-HERRERO AND SERGIO GAVILÁ: Posible impacto de Basilea Il en los países emergentes.

0607 ESTHER GORDO, JAVIER JAREÑO AND ALBERTO URTASUN: Radiografía del sector de servicios en España.

0608 JUAN AYUSO, ROBERTO BLANCO AND FERNANDO RESTOY: House prices and real interest rates in Spain.

0701 JOSÉ LUIS MALO DE MOLINA: Los principales rasgos y experiencias de la integración de la economía española en la UEM.

0702 ISABEL ARGIMÓN, FRANCISCO DE CASTRO AND ÁNGEL LUIS GÓMEZ: Una simulación de los efectos de la reforma del IRPF sobre la carga impositiva.

0703 YENER ALTUNBAŞ, ALPER KARA AND ADRIAN VAN RIXTEL: Corporate governance and corporate ownership: The investment behaviour of Japanese institutional investors.

0704 ARTURO MACÍAS AND ÁLVARO NASH: Efectos de valoración en la posición de inversión internacional de España.

0705 JUAN ÁNGEL GARCÍA AND ADRIAN VAN RIXTEL: Inflation-linked bonds from a central bank perspective.

0706 JAVIER JAREÑO: Las encuestas de opinión en el análisis coyuntural de la economía española.

0801 MARÍA J. NIETO AND GARRY J. SCHINASI: EU framework for safeguarding financial stability: Towards an analytical benchmark for assessing its effectiveness.

0802 SILVIA IRANZO: Delving into country risk. (There is a Spanish version of this edition with the same number.)

0803 OLYMPIA BOVER: The Spanish survey of household finances (EFF): Description and methods of the 2005 wave.

0804 JAVIER DÍAZ-CASSOU, AITOR ERCE-DOMÍNGUEZ AND JUAN J. VÁZQUEZ-ZAMORA: Recent episodes of sovereign debt restructurings. A case-study approach.

0805 JAVIER DÍAZ-CASSOU, AITOR ERCE-DOMÍNGUEZ AND JUAN J. VÁZQUEZ-ZAMORA: The role of the IMF in recent sovereign debt restructurings: Implications for the policy of lending into arrears.

0806 MIGUEL DE LAS CASAS AND XAVIER SERRA: Simplification of IMF lending. Why not just one flexible credit facility?

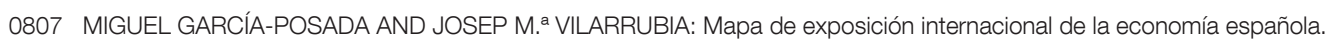

0808 SARAI CRIADO AND ADRIAN VAN RIXTEL: Structured finance and the financial turmoil of 2007-2008: An introductory overview. (There is a Spanish version of this edition with the same number.)

0809 FRANCISCO DE CASTRO AND JOSÉ M. GONZÁLEZ-MÍNGUEZ: La composición de las finanzas públicas y el crecimiento a largo plazo: Un enfoque macroeconómico.

0810 OLYMPIA BOVER: THE DYNAMICS OF HOUSEHOLD INCOME AND WEALTH: results from the panel of the Spanish survey of household finances (EFF) 2002-2005. (The original Spanish version has the same number.)

0901 ÁNGEL ESTRADA, JUAN F. JIMENO AND JOSÉ LUIS MALO DE MOLINA: THE SPANISH ECONOMY IN EMU: THE FIRST TEN YEARS. (THE ORIGINAL SPANISH VERSION HAS THE SAME NUMBER.) 
0902 ÁNGEL ESTRADA AND PABLO HERNÁNDEZ DE COS: Oil prices and their effect on potential output. (The original Spanish version has the same number.)

0903 PALOMA LÓPEZ-GARCÍA, SERGIO PUENTE AND ÁNGEL LUIS GÓMEZ: Employment generation by small firms in Spain.

0904 LUIS J. ÁLVAREZ, SAMUEL HURTADO, ISABEL SÁNCHEZ AND CARLOS THOMAS: The impact of oil price changes on Spanish and euro area consumer price inflation.

0905 CORAL GARCIA, ESTHER GORDO, JAIME MARTÍNEZ-MARTíN AND PATRY TELLO: Una actualización de las funciones de exportación e importación de la economía española.

1001 L. J. ÁlVAREZ, G. BULLIGAN, A. CABRERO, L FERRARA AND H. STAHL: Housing cycles in the major euro area countries.

1002 SONSOLES GALLEGO, SÁNDOR GARDÓ, REINER MARTIN, LUIS MOLINA AND JOSÉ MARÍA SERENA: The impact of the global economic and financial crisis on Central Eastern and SouthEastern Europe (CESEE) and Latin America.

1101 LUIS ORGAZ, LUIS MOLINA AND CARMEN CARRASCO: El creciente peso de las economías emergentes en la economía y gobernanza mundiales. Los países BRIC.

1102 KLAUS SCHMIDT-HEBBEL: Central banking in Latin America: changes, achievements, challenges. (There is a Spanish version of this edition with the same number.)

1103 OLYMPIA BOVER: The Spanish Survey of Household Finances (EFF): description and methods of the 2008 wave.

1104 PABLO HERNÁNDEZ DE COS, MARIO IZQUIERDO AND ALBERTO URTASUN: An estimate of the potential growth of the Spanish economy. (There is a Spanish version of this edition with the same number.)

\section{BANCODEESPAÑA}

Eurosistema
Unidad de Publicaciones

Alcalá 522, 28027 Madrid

Telephone +3491338 6363. Fax +34913386488

E-mail: publicaciones@bde.es www.bde.es 